\title{
Zn(ferulate)-LSH Systems as Multifunctional Filters
}

\author{
Gustavo Pereira Saito ${ }^{1}$, Ana Carolina Lanfredi Matsumoto ${ }^{1}$, Renata Pires Assis ${ }^{2}$, Iguatemy Lourenço Brunetti ${ }^{2}$, \\ Marco Aurélio Cebim ${ }^{1}$ and Marian Rosaly Davolos ${ }^{1, * \text { (D) }}$
}

1 Institute of Chemistry, São Paulo State University (Unesp), Araraquara 14800-060, São Paulo, Brazil; gustavopsaito@gmail.com (G.P.S.); carol.matsumoto@hotmail.com (A.C.L.M.); marco.cebim@unesp.br (M.A.C.)

2 School of Pharmaceutical Sciences, São Paulo State University (Unesp), Araraquara 14800-903, São Paulo, Brazil; renatapires_17@hotmail.com (R.P.A.); iguatemy.brunetti@unesp.br (I.L.B.)

* Correspondence: marian.davolos@unesp.br; Tel.: +55-016-33019634

check for updates

Citation: Saito, G.P.; Matsumoto, A.C.L.; Assis, R.P.; Brunetti, I.L.; Cebim, M.A.; Davolos, M.R. $\mathrm{Zn}$ (ferulate)-LSH Systems as Multifunctional Filters. Molecules 2021, 26, 2349. https://doi.org/ $10.3390 /$ molecules 26082349

Academic Editor: Diego Sampedro

Received: 29 November 2020 Accepted: 29 December 2020 Published: 17 April 2021

Publisher's Note: MDPI stays neutral with regard to jurisdictional claims in published maps and institutional affiliations.

Copyright: (C) 2021 by the authors. Licensee MDPI, Basel, Switzerland. This article is an open access article distributed under the terms and conditions of the Creative Commons Attribution (CC BY) license (https:/ / creativecommons.org/licenses/by/ $4.0 /)$.

\begin{abstract}
Excessive UV solar radiation exposure causes human health risks; therefore, the study of multifunctional filters is important to skin UV protective ability and also to other beneficial activities to the human organism, such as reduction of reactive oxygen species (ROS) responsible for cellular damages. Potential multifunctional filters were obtained by intercalating of ferulate anions into layered simple metal hydroxides (LSH) through anion exchange and precipitation at constant $\mathrm{pH}$ methods. Ultrasound treatment was used in order to investigate the structural changes in LSHferulate materials. Structural and spectroscopic analyses show the formation of layered materials composed by a mixture of LSH intercalated with ferulate anions, where carboxylate groups of ferulate species interact with LSH layers. UV-VIS absorption spectra and in vitro SPF measurements indicate that LSH-ferulate systems have UV shielding capacity, mainly UVB protection. The results of reactive species assays show the ability of layered compounds in capture $\mathrm{DPPH}^{\bullet}, \mathrm{ABTS}^{\bullet+}, \mathrm{ROO}^{\bullet}$, and $\mathrm{HOCl} / \mathrm{OCl}^{-}$reactive species. LSH-ferulate materials exhibit antioxidant activity and singular optical properties that enable their use as multifunctional filters.
\end{abstract}

Keywords: layered single metal hydroxides; hydroxycinnamic anions; intercalation; ultrasound treatment; UV protection; antioxidant activity

\section{Introduction}

Solar ultraviolet radiation (UV) is important for living organisms [1], especially humans [2], because it induces photochemical reactions responsible for the development and survival of these living species [3]. However, excessive UV radiation exposure causes damaging biological effects in the human organism [1-6] such as sunburns, premature aging, irregular skin pigmentation, and skin cancer. Moreover, UV radiation can be considered an occupational risk [7] due to people being exposed to sunlight throughout their lives. Therefore, sun protection is essential to minimize human health damages.

The chemical compounds that absorb and/or scatter UV radiation without changes in their physicochemical properties or do not decompose are denominated inorganic or organic filters [8]. These compounds are optical filters [9,10], which attenuate UV light and can transmit other radiations that compose solar spectrum. The UV shielding capacity of inorganic or organic filters makes them active constituents of the photoprotective products, e.g., sunscreens [11].

Organic filters are molecules that have chromophore groups [12] commonly with a high degree of $\pi$-conjugated systems. The UV absorption of organic filters involves electronic transitions between HOMO-LUMO orbitals, which often provide $\pi \rightarrow \pi^{*}$ and/or $n \rightarrow \pi^{*}$ transitions [3,12]. Among organic filters, hydroxycinnamic acids have been widely used in sunscreens due to UV shielding ability, low dermal toxicity, and less harmful to the environment [13-15]. An example of these molecules is the 3-(4-hydroxy-3- 
methoxyphenyl)prop-2-enoic acid (ferulic acid $-\mathrm{C}_{10} \mathrm{H}_{10} \mathrm{O}_{4}$ ). In general, hydroxycinnamic acids are organic compounds present in plant metabolism [16], which are easily obtained by extraction and separation methods of natural products [17]. A characteristic property of hydroxycinnamic acids is the antioxidant activity [18].

A problem related to organic filters is the decomposition of these compounds when subjected to certain conditions $[5,19]$ such as temperature and oxidizing media. This decomposition changes the optical properties of the chromophore species, decreasing UV protection efficiency [20]. In this perspective, the thermo, chemical, and photochemical stability of organic filters can be increased and enhance their UV shielding capacity by intercalating them into layered simple metal hydroxides (LSH). The LSH are layered-structure materials that have metal-hydroxyl host layers with or without charge-balancing anions in the interlayer spacing [21]. One type of LSH structure is derived from brucite mineral, where a part of the hydroxide groups of brucite-like layers has been replaced by anions or water molecules [22,23]. In the substitution of hydroxyl anions by water molecules, interlayer anions must be present in the second coordination sphere in order to neutralize the positively charged layers [23]. These LSH materials, also named layered hydroxide salts [23], present themselves as having the following formula $\mathrm{M}^{2+}(\mathrm{OH})_{2-\mathrm{x}}\left(\mathrm{A}^{\mathrm{n}-}\right)_{\mathrm{x} / \mathrm{n}} \cdot \mathrm{zH}_{2} \mathrm{O}$ $\left(\mathrm{M}^{2+}=\right.$ metal ion and $\mathrm{A}^{\mathrm{n}-}=$ interlayer anion). The intercalation of organic filters in LSH has been reported in the literature [24-29] due to broad-spectrum filters that were obtained having low skin irritability and thermal stability. However, the scientific studies do not show the UV shielding ability combined to antioxidant activity of LSH intercalated with organic anions.

Therefore, the study of intercalating hydroxycinnamic species in the LSH is of great significance for the development of materials with UV radiation protection, high photochemical stability, low toxicity, and antioxidant capacity, i.e., multifunctional filters. Thus, this work aims to investigate potential multifunctional filters obtained by the interaction of 3-(4-hydroxy-3-methoxyphenyl)prop-2-enoic acid (ferulic acid), in its anionic form, in the layered zinc hydroxide nitrate $\left(\mathrm{Zn}-\mathrm{NO}_{3}-\mathrm{LSH}\right)$ matrix, emphasizing the spectroscopic characterization and antioxidant activity of the layered materials.

\section{Results and Discussion}

According to synthetic methods and parameters used to obtain the LSH materials, in this work, the zinc hydroxide nitrate host matrix was designated $\mathrm{Zn}-\mathrm{NO}_{3}-\mathrm{LSH}$. LSHferulate material synthesized by the anion exchange method was named $\mathrm{Zn}$-fel-LSH/ A and LSH-ferulate materials prepared by the precipitation method with $\mathrm{Zn}^{2+} / \mathrm{C}_{10} \mathrm{H}_{9} \mathrm{O}_{4}{ }^{-}=3$, 4 and 5 molar ratio were designated $\mathrm{Zn}$-fel(3)-LSH, $\mathrm{Zn}$-fel(4)-LSH, and $\mathrm{Zn}$-fel(5)-LSH, respectively. In addition, $\mathrm{LSH}$ intercalated with ferulate anions synthesized by precipitation method with the $\mathrm{Zn}^{2+} / \mathrm{C}_{10} \mathrm{H}_{9} \mathrm{O}_{4}{ }^{-}=4$ molar ratio and subjected to ultrasound treatment for 10, 20, and $30 \mathrm{~min}$ were named Zn-fel(4)-LSH/U10, Zn-fel(4)-LSH/U20, and Zn-fel(4)$\mathrm{LSH} / \mathrm{U} 30$, respectively.

Comparing the XRD pattern of the $\mathrm{Zn}-\mathrm{NO}_{3}-\mathrm{LSH}$ host matrix with the JCPDS-PDF $\mathrm{n}^{\circ} 72-627$ card corresponding to zinc hydroxide nitrate (monoclinic unit cell and space group $\mathrm{C} 2 / \mathrm{m}$ ) and also comparing it to a series of LSH materials described in the literature [25-31], it is verified that the layered zinc hydroxide nitrate formation has regular stacking of sequential layers and phase purity (Figure A1). In the XRD pattern of the $\mathrm{Zn}-\mathrm{NO}_{3}-\mathrm{LSH}$, basal reflections (h00) situated in the low-angle region of $2 \theta$ are attributed to layer stacking, which is associated to basal distance $[23,25]$. The basal distance depends on size, geometry, conformation, and interlayer interactions of anionic species intercalated [25]. The other diffraction peaks of the layered zinc hydroxide nitrate are assigned to layered structures [32].

The XRD patterns of LSH-ferulate materials (Figures 1 and 2) show characteristic diffraction peaks of the $\mathrm{Zn}-\mathrm{NO}_{3}-\mathrm{LSH}$ matrix, which indicate the formation of $\mathrm{LSH}$ materials. However, basal reflections of LSH-ferulate materials are shifted to smaller angles when compared with those of the host matrix. This displacement indicates the increase of 
the basal distance (Table 1) caused by intercalation of ferulate anions. Basal distance is calculated from the interplanar distance $\left(\mathrm{d}_{\mathrm{hkl}}\right)$ of respective basal reflections and interlayer spacing corresponds to difference between basal distance and zinc hydroxide nitrate sheet thickness [33]. Considering that the charge density of the layer and layered structure remain intact after the intercalation of anionic species [27] and assuming that there are only electrostatic and/or intermolecular interactions into interlayer galleries, the value of the zinc hydroxide nitrate sheet thickness corresponds to $10.00 \AA ̊$ [33].

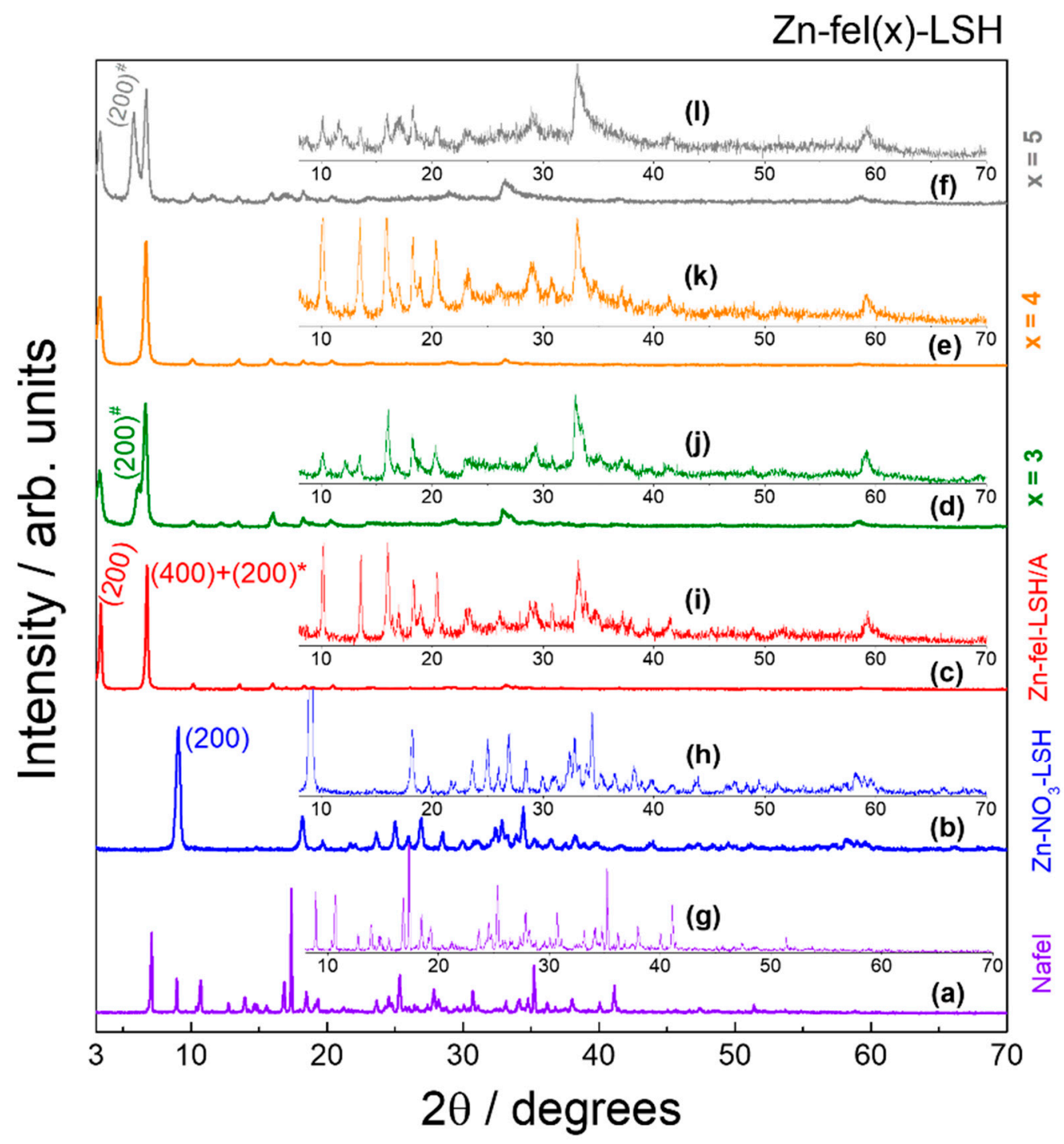

Figure 1. XRD patterns of (a) sodium ferulate salt (Nafel- $\mathrm{NaC}_{10} \mathrm{H}_{9} \mathrm{O}_{4}$ ), (b) Zn- $\mathrm{NO}_{3}$-LSH host matrix, (c) Zn-fel-LSH/A, (d) $\mathrm{Zn}$-fel(3)-LSH, (e) Zn-fel(4)-LSH, and (f) Zn-fel(5)-LSH in the 3-70 /2 $\theta$ region. Figures inserted show magnified X-ray diffraction lines of (g) Nafel salt $\left(\mathrm{NaC}_{10} \mathrm{H}_{9} \mathrm{O}_{4}\right)$, (h) $\mathrm{Zn}-\mathrm{NO}_{3}-\mathrm{LSH}$ host matrix, (i) Zn-fel-LSH/A, (j) Zn-fel(3)-LSH, (k) $\mathrm{Zn}$-fel(4)-LSH, and (1) $\mathrm{Zn}$-fel(5)-LSH in the $8-70^{\circ} / 2 \theta$ region. 


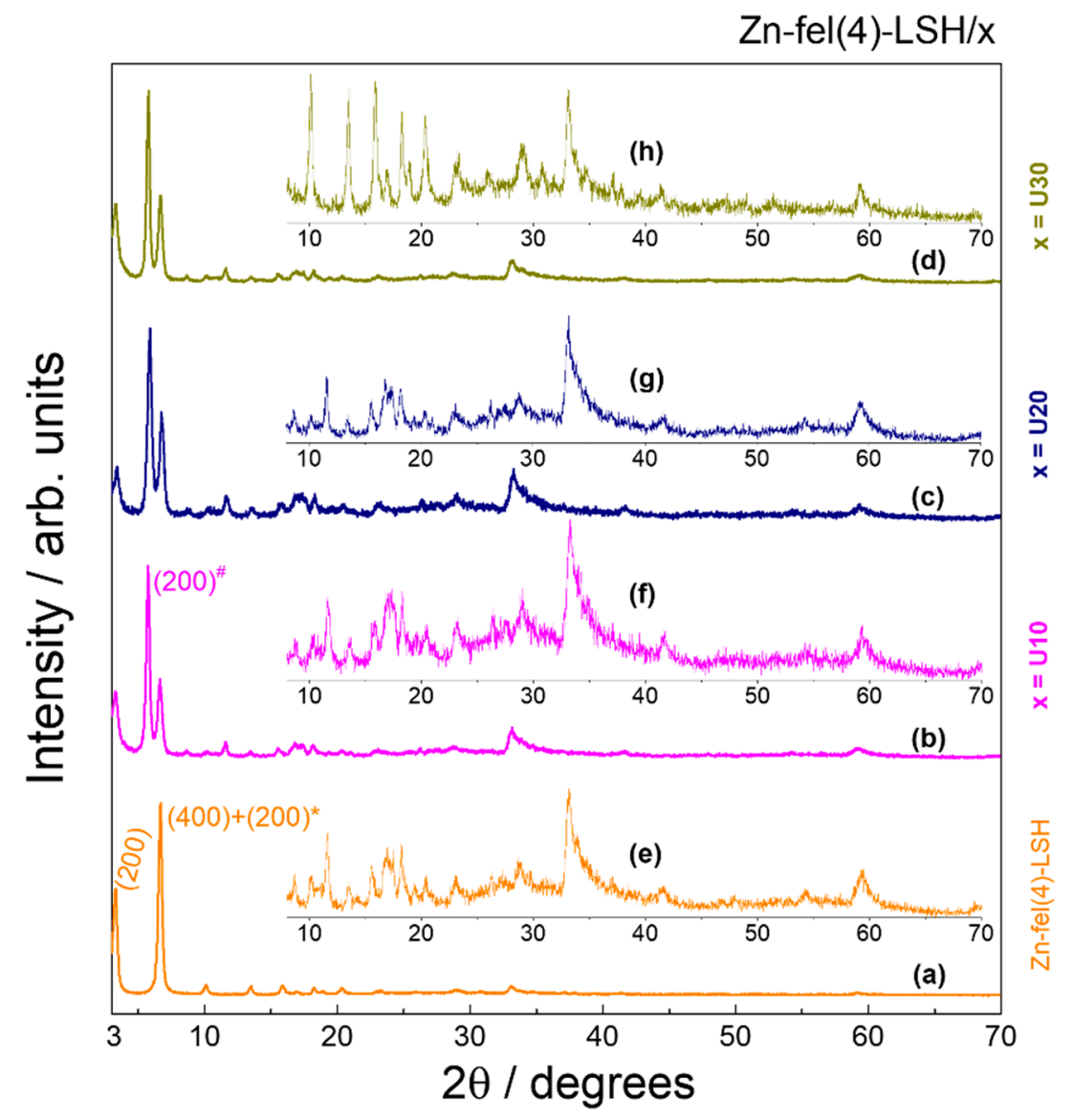

Figure 2. XRD patterns of (a) Zn-fel(4)-LSH, (b) Zn-fel(4)-LSH/U10, (c) Zn-fel(4)-LSH/U20, and (d) $\mathrm{Zn}$-fel(4)-LSH/U30 in the $3-70^{\circ} / 2 \theta$ region. Figures inserted show magnified X-ray diffraction lines of (e) Zn-fel(4)-LSH, (f) Zn-fel(4)-LSH/U10, (g) Zn-fel(4)-LSH/U20, and (h) Zn-fel(4)$\mathrm{LSH} / \mathrm{U} 30$ in the $8-70^{\circ} / 2 \theta$ region.

Table 1. Interplanar distance $\mathrm{d}_{200}$, basal distance, and interlayer spacing of LSH materials.

\begin{tabular}{|c|c|c|c|}
\hline Sample & $\mathrm{d}_{200} / \AA$ & Basal Distance/Å & Interlayer Spacing/Å \\
\hline $\mathrm{Zn}-\mathrm{NO}_{3}-\mathrm{LSH}$ & 9.74 & 9.74 & - \\
\hline \multirow[t]{2}{*}{ Zn-fel-LSH/A } & 26.30 & 26.17 & 16.17 \\
\hline & 13.08 * & $13.05 *$ & $3.05 *$ \\
\hline \multirow[t]{3}{*}{ Zn-fel(3)-LSH } & 27.10 & 26.54 & 16.54 \\
\hline & 14.35 * & $14.48^{*}$ & $4.48 *$ \\
\hline & $13.27^{\#}$ & $13.19^{\#}$ & $3.19^{\#}$ \\
\hline \multirow[t]{2}{*}{ Zn-fel(4)-LSH } & 26.94 & 26.45 & 16.45 \\
\hline & 13.23 * & 13.17 * & $3.17^{*}$ \\
\hline \multirow[t]{3}{*}{ Zn-fel(4)-LSH/U10 } & 26.94 & 26.48 & 16.48 \\
\hline & $15.40 *$ & $15.33 *$ & $5.33 *$ \\
\hline & $13.31^{\#}$ & $13.23^{\#}$ & $3.23^{\#}$ \\
\hline \multirow[t]{3}{*}{ Zn-fel(4)-LSH/U20 } & 25.83 & 25.99 & 15.99 \\
\hline & 14.98 * & 15.14 * & $5.14 *$ \\
\hline & 13.00 \# & $13.03^{\#}$ & $3.03^{\#}$ \\
\hline \multirow[t]{3}{*}{ Zn-fel(4)-LSH/U30 } & 26.61 & 26.44 & 16.44 \\
\hline & $15.29 *$ & 15.28 * & $5.28 *$ \\
\hline & $13.27^{\#}$ & 13.17 & 3.17 \\
\hline \multirow{3}{*}{ Zn-fel(5)-LSH } & 26.77 & 26.37 & 16.37 \\
\hline & 15.24 * & 15.27 * & $5.27 *$ \\
\hline & $13.15^{\#}$ & $13.12^{\#}$ & $3.12^{\#}$ \\
\hline
\end{tabular}

*\# Different LSH phases. 
Regardless of synthetic methods and/or the $\mathrm{Zn}^{2+} / \mathrm{C}_{10} \mathrm{H}_{9} \mathrm{O}_{4}{ }^{-}$molar ratio used, LSH-ferulate samples are composed to a mixture of LSH phases that have different arrangements of ferulate anions in the interlayer region. In addition, the $\mathrm{Zn}^{2+} / \mathrm{C}_{10} \mathrm{H}_{9} \mathrm{O}_{4}{ }^{-}$ molar ratio is a synthesis parameter that influences the number of phases present in the $\mathrm{Zn}$-fel(3)-LSH, Zn-fel(4)-LSH, and Zn-fel(5)-LSH materials; therefore, the $\mathrm{Zn}^{2+}$ and ferulate ions quantities are determinant to the formation of zinc hydroxide layers and interlayer arrangements of ferulate anions in these materials.

Ultrasound treatment is commonly used on layered materials to modify structural and morphological properties and/or to obtain ultrathin two-dimensional materials [34]. Considering the synthesis time and lowest number of LSH phases, the Zn-fel(4)-LSH material was subjected to ultrasound treatment for different times, giving rise to $\mathrm{Zn}$-fel(4)$\mathrm{LSH} / \mathrm{U10}, \mathrm{Zn}$-fel(4)-LSH/U20, and Zn-fel(4)-LSH/U30 samples. In the XRD patterns of $\mathrm{Zn}$-fel(4)-LSH/U10, Zn-fel(4)-LSH/U20, and Zn-fel(4)-LSH/U30 materials (Figure 2), it is observed the emergence of basal reflections associated to a new LSH phase present in the composition of these layered compounds. Therefore, cavitation effect produced by ultrasound treatment [35] provides the formation of new layered structures.

$\mathrm{LSH}$-ferulate materials have lower zeta potential values than the $\mathrm{Zn}-\mathrm{NO}_{3}-\mathrm{LSH}$ matrix (Figure 3) due to the interlayer and/or surface interactions between ferulate anions and LSH layers. This interfacial behavior is similar to those described for zinc layered hydroxide salts intercalated with organic anions [36,37]. The Zn-fel-LSH/A sample displays negative zeta potential, which indicates that the layered material has a negatively charged surface [38]. While, the other LSH-ferulate materials have a positively charged surface according to the zeta potentials obtained (Figure 3). The difference in the surface charge of the LSHmaterials is correlated to the quantity of ferulate anions adsorbed in the zinc hydroxide layers, which influences the structure of the electrical double layer on LSH surfaces, i.e., Stern layer and diffusion layer [39]. The anions adsorbed thermally vibrate and can leave the Stern layer, consequently, there are always anions in the diffusion layer [40]. Thus, the charge of LSH particle associated to the Stern layer depends on concentration and surface interactions of ferulate anions. The negative charge surface of the $\mathrm{Zn}$-fel-LSH/A sample comes from the greater amount of ferulate anions in the Stern layer that results in a smaller concentration of these anionic species in the diffuse layer. Therefore, the anion exchange method facilitates the adsorption of ferulate anions in the LSH host when compared to precipitation method. Moreover, zeta potentials of the LSH-ferulate materials depend on the $\mathrm{Zn}^{2+} / \mathrm{C}_{10} \mathrm{H}_{9} \mathrm{O}_{4}{ }^{-}$molar ratio and ultrasound treatment time. Probably, constituent LSH phases of layered materials limit the amount of ferulate anions adsorbed, which provides different zeta potential values.

The FTIR spectrum of the $\mathrm{Zn}-\mathrm{NO}_{3}$ - $\mathrm{LSH}$ matrix (Figure 4) shows a narrow band at $3576 \mathrm{~cm}^{-1}$ attributed to $\mathrm{O}-\mathrm{H}$ stretching of hydroxyl anions belonging to the zinc hydroxide layers $[25,41]$. In addition, it is observed broad bands centered at 3468 and $3292 \mathrm{~cm}^{-1}$ assigned to hydroxyl stretching vibrations, which correspond to water molecules and hydroxyl groups linked with nitrate anions, respectively [41]. The vibrational spectrum of the host matrix also exhibits nitrate bands $\left(v_{\mathrm{as}}=1369 \mathrm{~cm}^{-1}\right.$ and $\left.v_{\mathrm{s}}=1015 \mathrm{~cm}^{-1}\right)$ [42] and metal-oxygen vibrational modes $\left(631,521,467,430\right.$, and $\left.386 \mathrm{~cm}^{-1}\right)$ [41]. The FTIR spectrum of the sodium ferulate salt $\left(\mathrm{NaC}_{10} \mathrm{H}_{9} \mathrm{O}_{4}\right)$ (Figure 4 ) shows characteristic bands of hydroxycinnamic acids, such as aromatic ring vibrations $\left(1595,1450,1425\right.$, and $\left.1215 \mathrm{~cm}^{-1}\right)[43,44]$ and carboxylate stretching vibrations $\left(v_{\mathrm{as}}=1539 \mathrm{~cm}^{-1}\right.$ and $\left.v_{\mathrm{s}}=1379 \mathrm{~cm}^{-1}\right)$ [45]. Moreover, the vibrational spectrum presents narrow bands at 1165 and $1032 \mathrm{~cm}^{-1}$ attributed to C-O stretching of the phenol and methoxy group, respectively [45].

In the FTIR spectra of LSH-ferulate materials (Figures 4 and 5), characteristic bands of the ferulate anion are observed, such as $\mathrm{C}=\mathrm{C}$ (alkene) stretching $\left(1634 \mathrm{~cm}^{-1}\right)$ and $\mathrm{C}=\mathrm{C}$ (ring) stretching $\left(1425 \mathrm{~cm}^{-1}\right)$, and typical bands of the LSH host assigned to hydroxyl stretching vibrations and also the zinc-oxygen vibrational modes. Moreover, the phenol, methoxy, and carboxylate bands are shifted when compared to those of the ferulate anion. These vibrational shifts indicate that interactions between positive zinc hydroxide layers and ferulate 
anions occur through the polar groups of the guest anion. Host-guest interactions in these layered materials are also proven by enlargement and/or overlapping of hydroxyl bands and the displacement of metal-oxygen vibrational modes when compared to those of the $\mathrm{Zn}-\mathrm{NO}_{3}$-LSH matrix. It is important to emphasize that methoxy and hydroxyl groups of ferulate anions interact with hydroxyl groups and water molecules of the LSH host by hydrogen bonds.

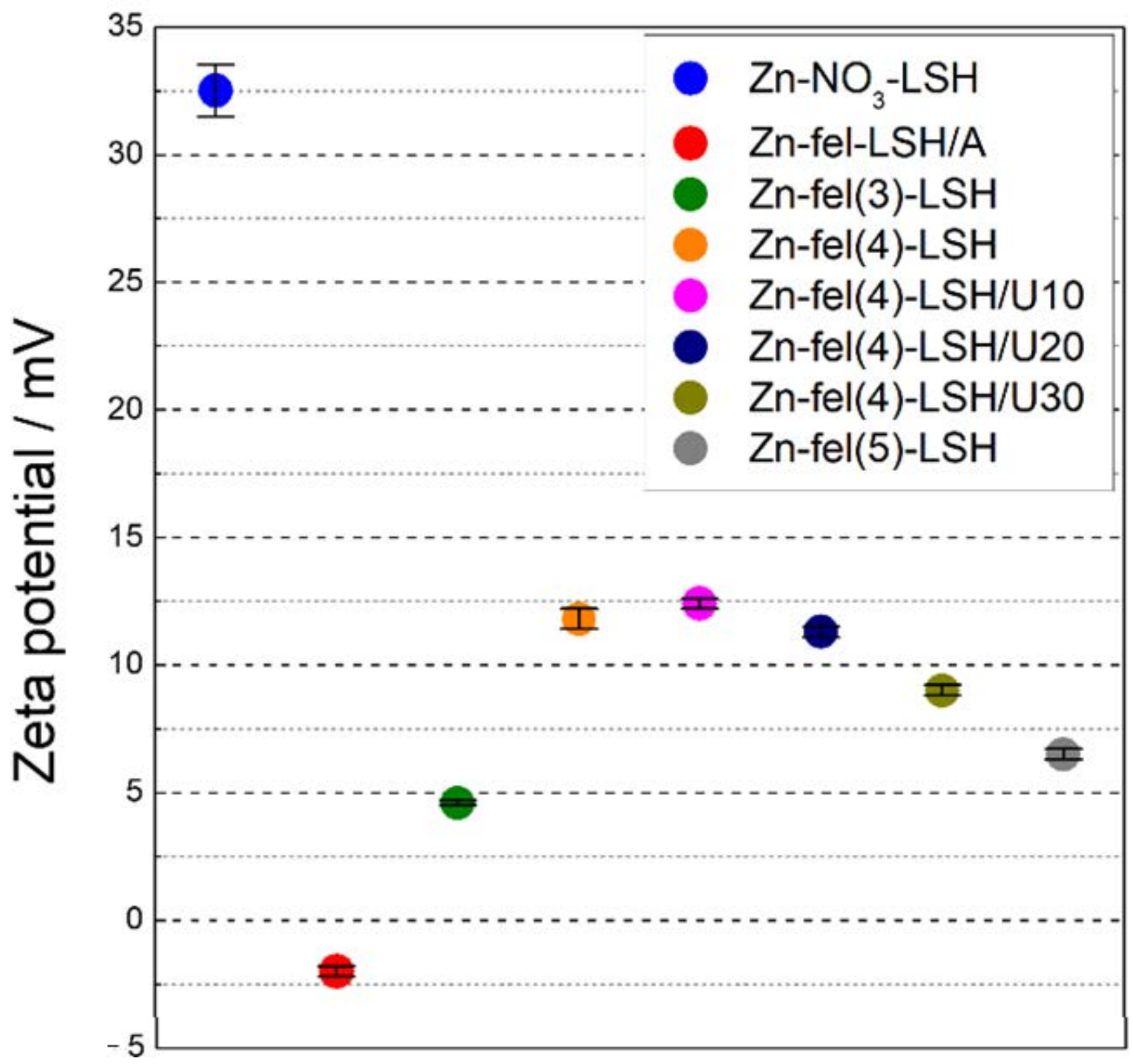

Figure 3. Zeta potential values of the $\mathrm{Zn}-\mathrm{NO}_{3}-\mathrm{LSH}$ matrix and $\mathrm{LSH}$-ferulate materials. 


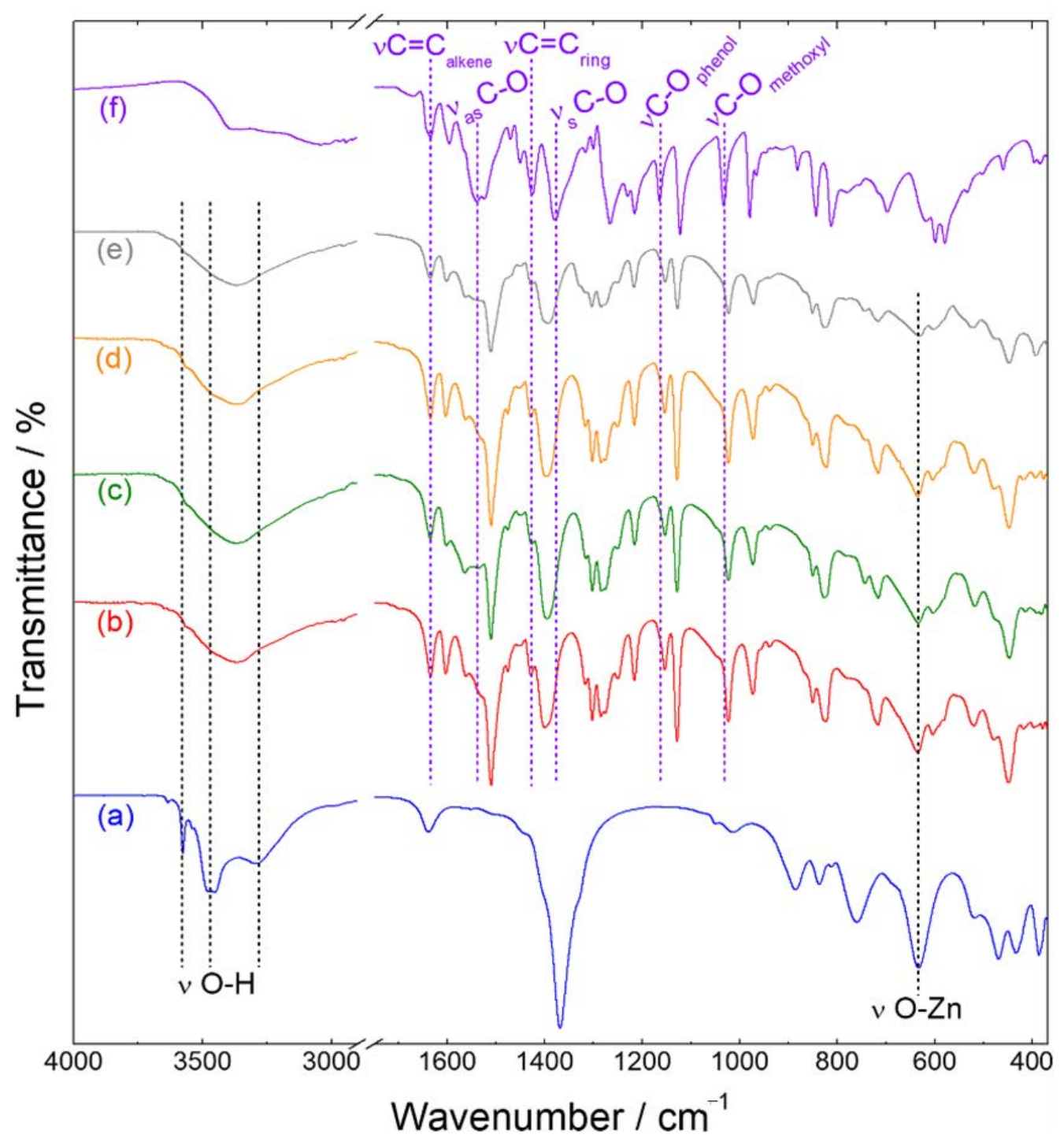

Figure 4. FTIR spectra of (a) Zn-NO $\mathrm{NO}_{3}$-LSH host matrix, (b) Zn-fel-LSH/A, (c) Zn-fel(3)-LSH, (d) Znfel(4)-LSH, (e) $\mathrm{Zn}$-fel(5)-LSH, and (f) Nafel salt $\left(\mathrm{NaC}_{10} \mathrm{H}_{9} \mathrm{O}_{4}\right)$.

Comparing the FTIR spectra of Zn-fel(4)-LSH/U10, Zn-fel(4)-LSH/U20, and Znfel(4)-LSH/U30 samples with the Zn-Fel(4)-LSH spectrum (Figure 5), it is observed the enlargement of the hydroxyl band of LSH samples subjected to ultrasound treatment caused by modifications of surface and/or interlayer interactions between ferulate anions, water molecules, and/or hydroxyl groups from layers. In addition, the increase of the relative intensity of the hydroxyl band in the Zn-fel(4)-LSH/U10 and Zn-fel(4)-LSH/U30 materials can be associated to a greater amount of water molecules adsorbed and/or intercalated. Therefore, ultrasound cavitation that induces the break and/or the formation of different host-guest interactions in these layered materials is a function of the treatment time.

The carboxylate groups of ferulate anions can be coordinated to zinc ions in different ways; therefore, the frequency difference between carboxylate asymmetric and symmetric stretching vibrations $\left(\Delta v=v_{\mathrm{as}}-v_{\mathrm{s}}\right)$ gives information about the coordination mode [42] having the $\Delta v$ value of the sodium ferulate salt as reference. Thus, the monodentate coordination mode is found for $\Delta v$ values much greater than the reference salt due to the frequency increase of the carboxylate asymmetric stretching vibration and the frequency decrease of the symmetric stretching vibration when compared to those of the ionic compound [46]. The chelate-bidentate mode corresponds to $\Delta v$ values significantly lower than the reference salt because the frequency of the carboxylate asymmetric stretching 
vibration decreases and the frequency of the carboxylate symmetric stretching vibration increases [46]. The $\Delta v$ values for the bridging bidentate mode are close to the sodium ferulate salt value $[42,46]$.

According to the $\Delta v$ values obtained for LSH-ferulate materials (Table 2), carboxylate groups are bound to the $\mathrm{Zn}^{2+}$ ions from the layers via bridging bidentate and/or chelatebidentate mode. This result indicates that there are different interaction modes between ferulate anions and LSH layers, which can be associated to several arrangements of ferulate species in the interlayer spacing of layered materials. In addition, each LSH-ferulate sample has carboxylate groups coordinated to metal ions in two different ways. Therefore, constituent LSH phases of layered materials confirmed in XRD results (Figures 1 and 2) are directly related to coordination modes of the carboxylate groups assigned to ferulate anions. Thus, the coordination of guest anions causes zinc hydroxide sheet thickness changes, which explains the small interlayer spacing values situated in the 3-5 A range (Table 1).

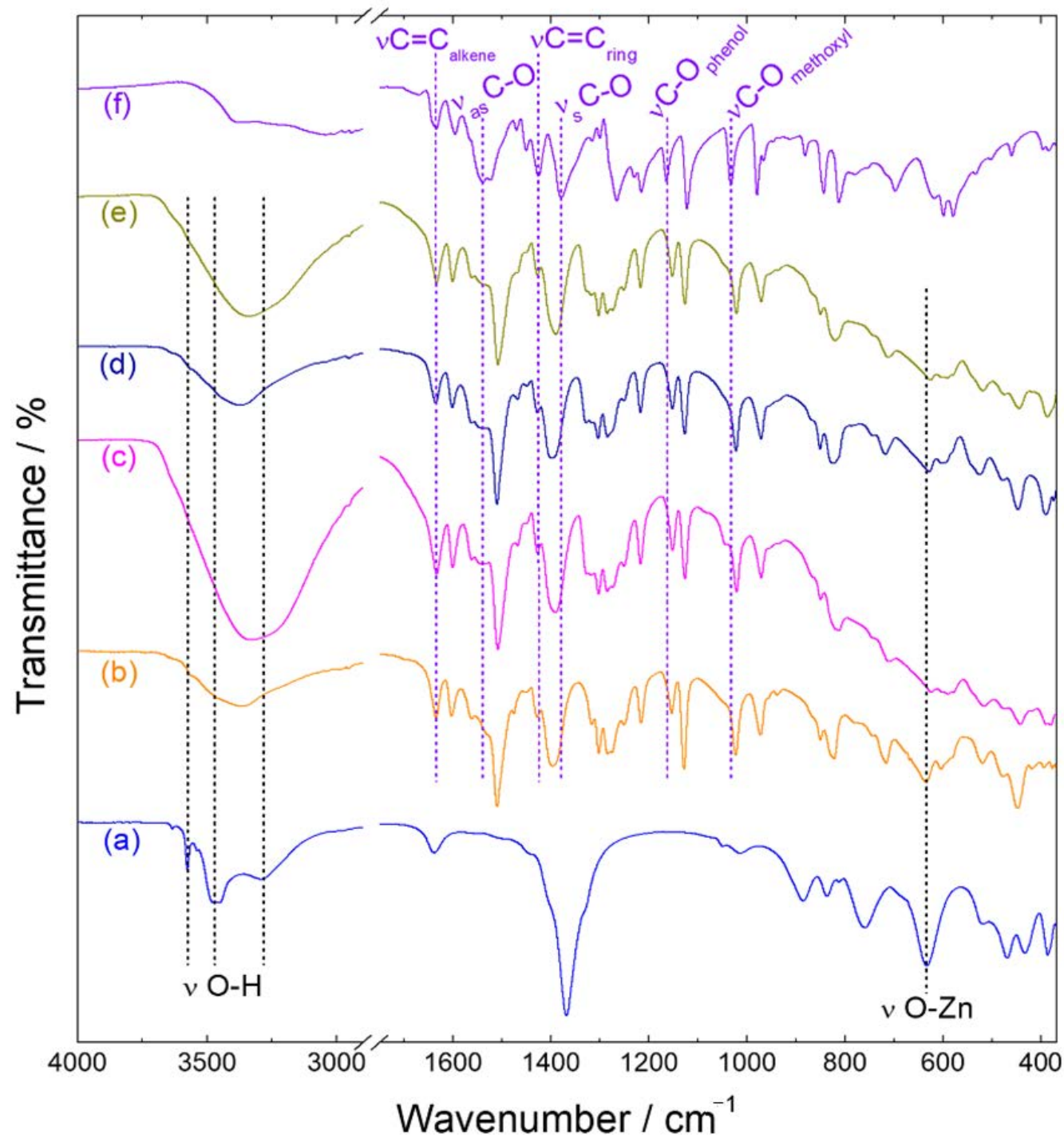

Figure 5. FTIR spectra of (a) Zn-NO 3 -LSH host matrix, (b) Zn-fel(4)-LSH, (c) Zn-fel(4)-LSH/U10, (d) Zn-fel(4)-LSH/U20, (e) Zn-fel(4)-LSH/U30, and (f) Nafel salt $\left(\mathrm{NaC}_{10} \mathrm{H}_{9} \mathrm{O}_{4}\right)$. 
Table 2. Frequencies of the carboxylate asymmetric and symmetric stretching modes and frequency difference values $\left(\Delta v=v_{\mathrm{as}}-v_{\mathrm{s}}\right)$ between carboxylate stretching modes of the sodium ferulate salt (Nafel- $\mathrm{NaC}_{10} \mathrm{H}_{9} \mathrm{O}_{4}$ ) and LSH-ferulate materials.

\begin{tabular}{|c|c|c|c|}
\hline Sample & $v_{\mathrm{as}} / \mathrm{cm}^{-1}$ & $v_{\mathrm{s}} / \mathrm{cm}^{-1}$ & $\Delta v\left(v_{\text {as }}-v_{\mathrm{s}}\right) / \mathrm{cm}^{-1}$ \\
\hline Nafel & 1539 & 1379 & 160 \\
\hline \multirow[t]{2}{*}{ Zn-fel-LSH/A } & 1560 & \multirow{2}{*}{1400} & 160 \\
\hline & 1508 & & 108 * \\
\hline \multirow[t]{2}{*}{ Zn-fel(3)-LSH } & 1562 & \multirow{2}{*}{1394} & 168 \\
\hline & 1510 & & $116^{*}$ \\
\hline \multirow[t]{2}{*}{ Zn-fel(4)-LSH } & 1560 & \multirow{2}{*}{1394} & 166 \\
\hline & 1510 & & $116^{*}$ \\
\hline \multirow[t]{2}{*}{ Zn-fel(4)-LSH/U10 } & 1562 & \multirow{2}{*}{1390} & 172 \\
\hline & 1508 & & 118 * \\
\hline \multirow[t]{2}{*}{ Zn-fel(4)-LSH/U20 } & 1562 & \multirow{2}{*}{1398} & 164 \\
\hline & 1510 & & 112 * \\
\hline \multirow[t]{2}{*}{ Zn-fel(4)-LSH/U30 } & 1562 & \multirow{2}{*}{1391} & 171 \\
\hline & 1508 & & 117 * \\
\hline \multirow[t]{2}{*}{ Zn-fel(5)-LSH } & 1562 & \multirow{2}{*}{1394} & 168 \\
\hline & 1510 & & 116 * \\
\hline
\end{tabular}

* Different coordination mode assigned to the same LSH-ferulate material.

In the $\mathrm{Zn}$-fel-LSH/A material, the $\Delta v$ value equal to the Nafel salt $\left(\mathrm{NaC}_{10} \mathrm{H}_{9} \mathrm{O}_{4}\right)$ indicates an ionic mode of carboxylate groups attributed to ferulate anions. These ionic interactions of carboxylate groups can be associated to an excess amount of ferulate anions in the surface of the layered material as seen in the zeta potential results.

Considering the ferulate anion dimensions achieved by semi-empirical calculations $(1.8 \times 7.1 \times 9.4 \AA)$, interlayer distances of LSH-ferulate materials from XRD data (Table 1$)$ and host-guest interactions described in FTIR results, mono and/or bilayer arrangements of organic anions in the interlayer region are proposed. In the bilayer arrangements (Figure 6a), carboxylate groups of ferulate anions are close to the positive LSH layers and hydroxyl and methoxy groups are interacting with each other and/or water molecules in the interlayer spacing. The monolayer arrangements (Figure $6 \mathrm{~b}$ ) are formed by interactions between polar groups of ferulate anions and positively charge layers, which cause probably molecular structure distortions of the guest anion. Therefore, the interlayer spacing values of monolayer arrangements are associated with spatial orientations of ferulate species in the interlayer galleries.

The CIELab color diagram (Figure 7) shows that LSH-ferulate materials have a yellowish-white color; consequently, their use in sunscreen formulations do not compromise the desired aesthetics appearance for the cosmetic products. In the UV-VIS diffuse reflectance spectra (Figures A2 and A3), it is observed that LSH-ferulate materials have absorption edge situated in the $350-400 \mathrm{~nm}$ region similar to Nafel salt. Moreover, each layered material has a characteristic visible-light scattering $(400-800 \mathrm{~nm})$ due its particle size and refractive index associated to constituent LSH structures.

The absorption spectrum of the $\mathrm{Zn}-\mathrm{NO}_{3}-\mathrm{LSH}$ matrix (Figure 8) shows broad bands with maximum values at 220, 251, 287, and $296 \mathrm{~nm}$, which are assigned to electronic transitions of the nitrate anions intercalated $[47,48]$. This spectrum also exhibits an absorption band at $345 \mathrm{~nm}$ attributed to $\mathrm{VB} \rightarrow \mathrm{CB}$ transitions of the zinc hydroxide layers. The Nafel spectrum (Figure 8) presents characteristic absorption bands of hydroxycinnamic compounds situated in the $210-280 \mathrm{~nm}$ region, which are assigned to $\pi \rightarrow \pi^{*}$ electronic transitions [49,50]. In addition, a broad and intense band at $325 \mathrm{~nm}$ attributed to a mixture of $\pi \rightarrow \pi^{*}$ and $n \rightarrow \pi^{*}$ transitions $[49,50]$ is observed. These last electronic transitions correspond to carboxyl group and $\pi$-aromatic system of the ferulate anion. 


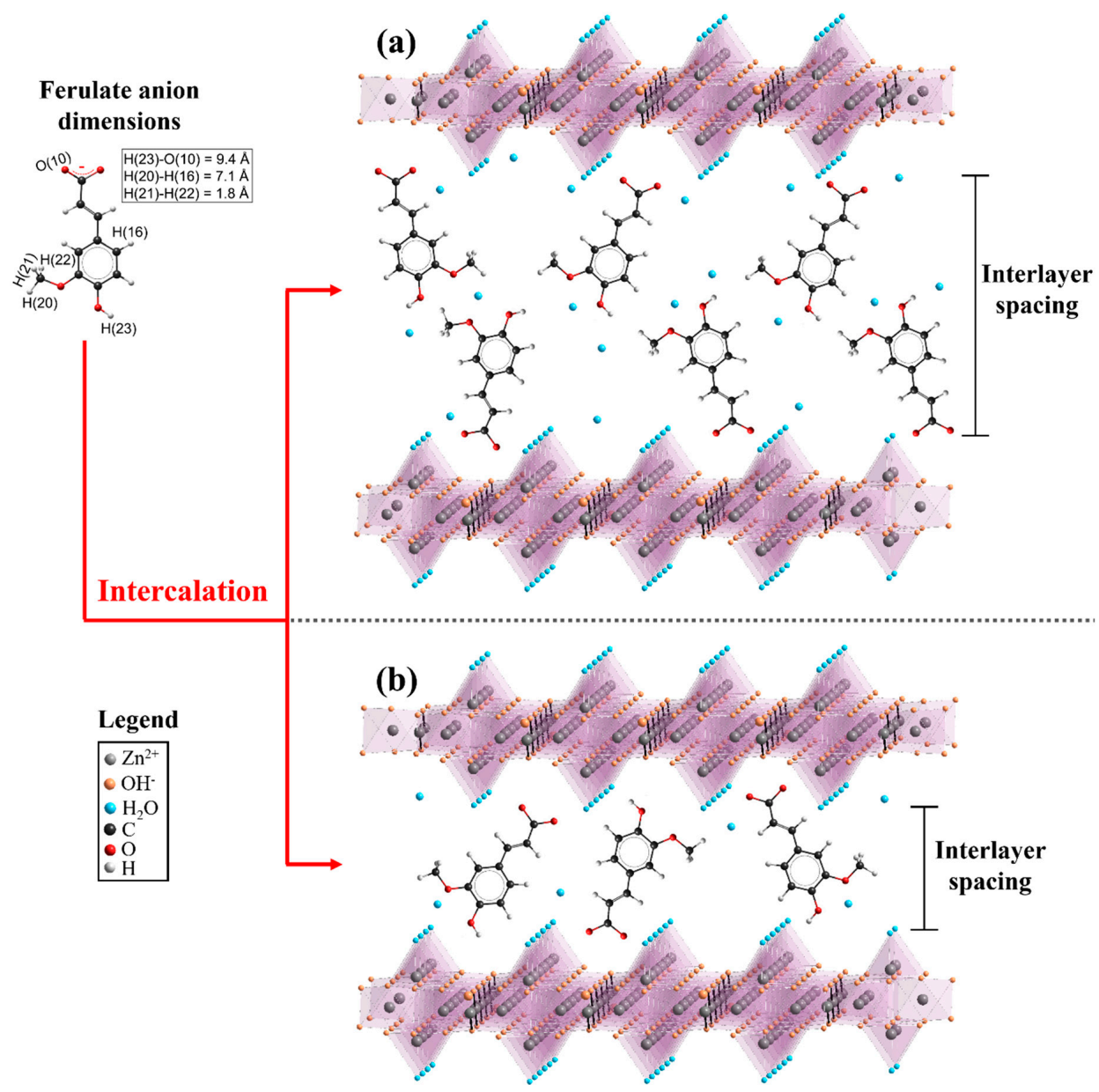

Figure 6. Schematic representations of proposed (a) bilayer and (b) monolayer arrangements for the ferulate anions in the LSH-ferulate materials.
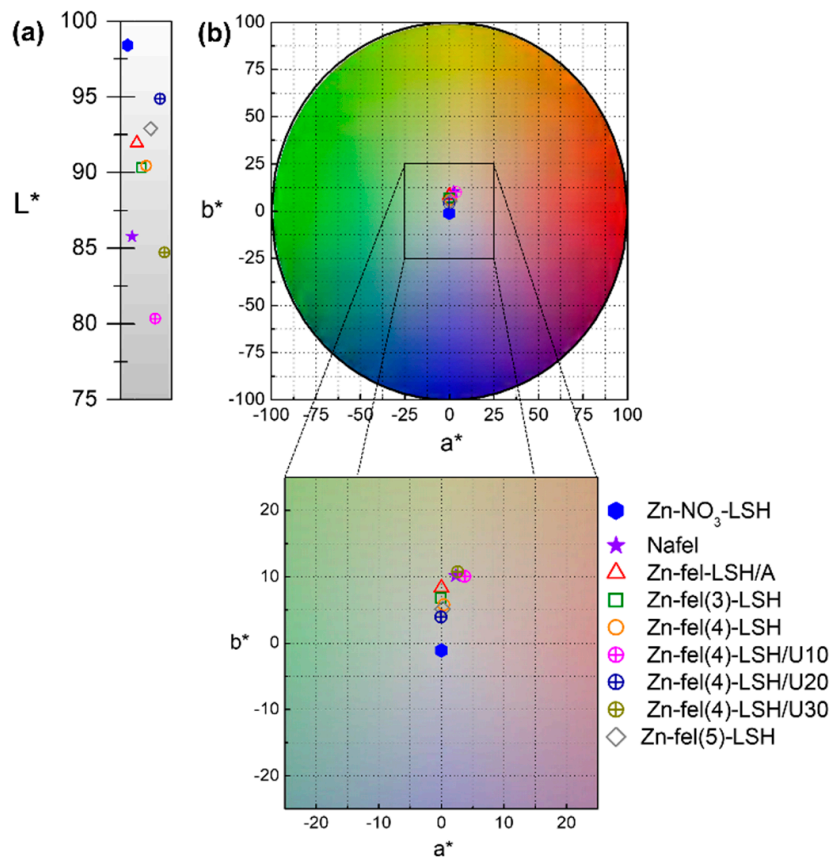

Figure 7. (a) Brightness scale; (b) Color scale corresponding to the CIELab color diagram of $\mathrm{Zn}-\mathrm{NO}_{3}$ LSH matrix, Nafel salt $\left(\mathrm{NaC}_{10} \mathrm{H}_{9} \mathrm{O}_{4}\right)$, and LSH-ferulate materials. 


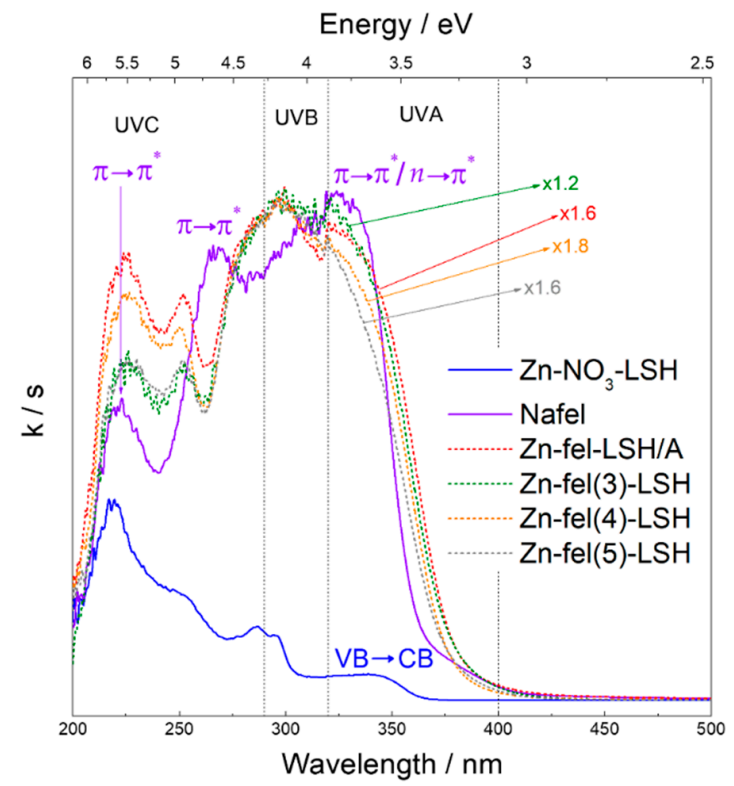

Figure 8. Absorption spectra of Zn-NO 3 -LSH, Zn-fel-LSH/A, Zn-fel(3)-LSH, Zn-fel(4)-LSH, Zn-fel(5)$\mathrm{LSH}$, and Nafel salt $\left(\mathrm{NaC}_{10} \mathrm{H}_{9} \mathrm{O}_{4}\right)$.

Absorption spectra of LSH-ferulate materials (Figures 8 and 9) show typical absorption bands of host matrix and ferulate anion, although these bands are shifted, enlarged, and/or overlapped when compared to those of $\mathrm{Zn}-\mathrm{NO}_{3}-\mathrm{LSH}$ matrix and Nafel salt. The absorption band situated in the 240-260 $\mathrm{nm}$ region corresponds to an overlapping of the nitrate band of the LSH host and hydroxycinnamic band assigned to $\pi \rightarrow \pi^{*}$ transitions of ferulate anions. This absorption band indicates the presence of nitrate anions in the LSH-ferulate materials, which are co-intercalated with ferulate anions in the interlayer galleries. Moreover, hostguest interactions in these layered materials provide the hydroxycinnamic band shifts due to changes in the $\pi$-aromatic system of ferulate anions. The enlarged absorption band in the $270-380 \mathrm{~nm}$ region is composed to the mixture of the $\mathrm{LSH}$ band attributed to $\mathrm{VB} \rightarrow \mathrm{CB}$ transitions and ferulate band assigned to a mixture of $\pi \rightarrow \pi^{*}$ and $n \rightarrow \pi^{*}$ transitions. The bathochromic shift of this band in the LSH-ferulate materials indicates that carboxylate groups are coordinated to the $\mathrm{Zn}^{2+}$ ions from the host layers. The bathochromic effect is associated to energy decrease of $\pi \rightarrow \pi^{*}$ transitions of carboxylate groups generally assigned to the energy stabilization of the $\pi$-system [50]. The five-membered ring structures can stabilize $\pi$-systems. According to FTIR results, ferulate anions are bound via bridging bidentate and/or chelate-bidentate mode, consequently, bridging bidentate mode can be suggested. The Zn-fel(4)-LSH/U10 and Zn-fel(4)-LSH/U30 materials have different absorption profiles than other LSH-ferulate materials. This difference provides evidence that ultrasonic cavitation also causes energy levels changes of the LSH-ferulate system due to modifications of surface and/or interlayer interactions between ferulate anions and host layers proven in the FTIR results. The UV absorption capacity of LSH-ferulate materials in the $210-380 \mathrm{~nm}$ region demonstrates their potential for applicability as active constituents of photoprotective products.

Considering the shortest synthesis time, ultrasound treatment effects, structural properties, and UV shielding ability, Zn-fel(4)-LSH and Zn-fel(4)-LSH/U10 materials were chosen as reference samples to investigate thermal decomposition behavior, antioxidant activity, and sun protection factor (SPF) performance of LSH intercalated with ferulate anions. TGA-DSC curves of Zn-fel(4)-LSH and Zn-fel(4)-LSH/U10 samples (Figure 10) show four main thermal events. The first two events associated to endothermic processes occur until $300{ }^{\circ} \mathrm{C}$ and correspond to loss of water molecules adsorbed and intercalated in the layered materials $[25,26]$. The further thermal events (exothermic processes) occur in the $300-450{ }^{\circ} \mathrm{C}$ temperature range and are attributed to the simultaneous decomposition of guest species (ferulate combustion) and LSH layers (layers dehydroxylation) $[25,26]$. 


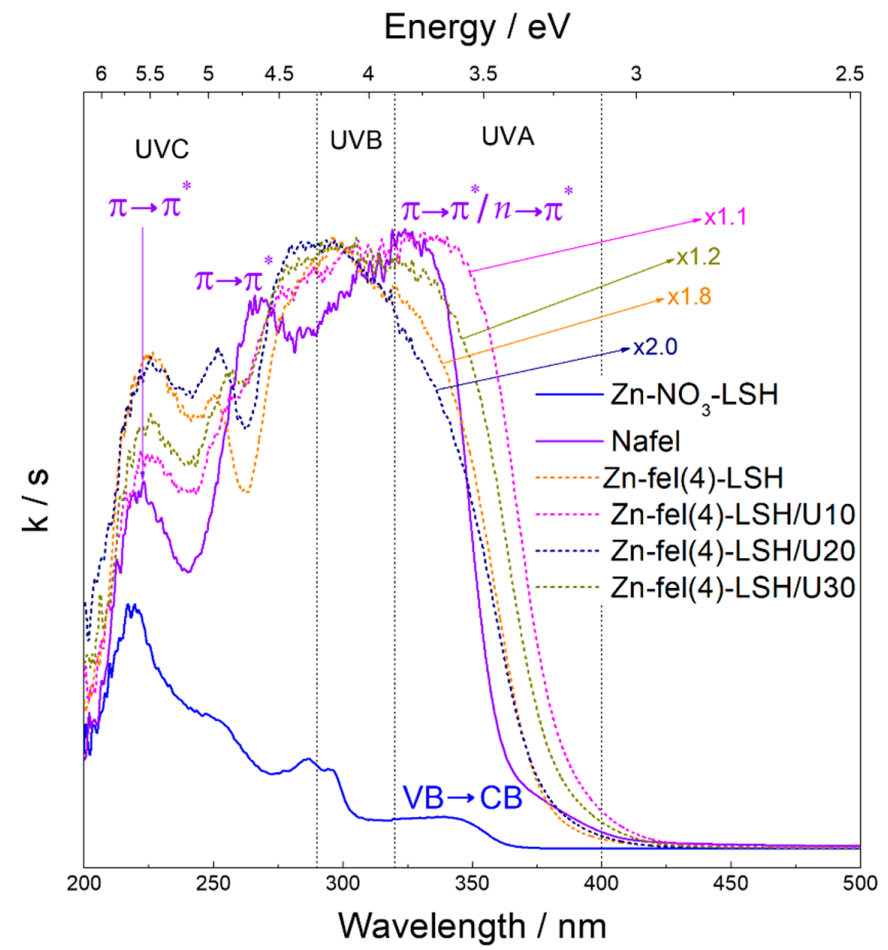

Figure 9. Absorption spectra of $\mathrm{Zn}-\mathrm{NO}_{3}-\mathrm{LSH}, \mathrm{Zn}$-fel(4)-LSH, Zn-fel(4)-LSH/U10, Zn-fel(4)-LSH/U20, $\mathrm{Zn}-\mathrm{fel}(4)-\mathrm{LSH} / \mathrm{U} 30$, and Nafel salt $\left(\mathrm{NaC}_{10} \mathrm{H}_{9} \mathrm{O}_{4}\right)$.
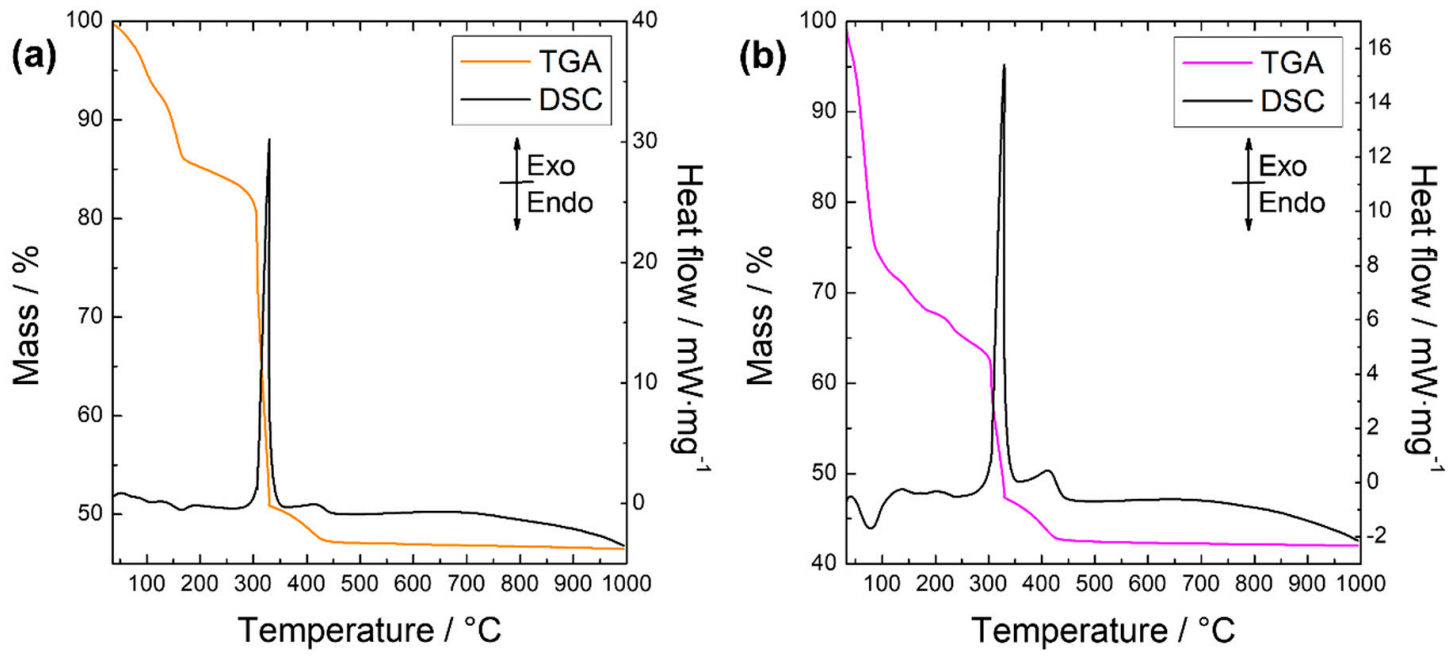

Figure 10. TGA-DSC curves of (a) Zn-fel(4)-LSH and (b) Zn-fel(4)-LSH/U10 samples.

Although the layered materials exhibit similar thermal decomposition profiles, the percentages of mass loss $(\mathrm{w} t \%)$ corresponding to main thermal events are different (Table 3). This difference in the chemical composition comes from the distinct LSH phases that compose the Zn-fel(4)-LSH and Zn-fel(4)-LSH/U10 materials as noted in the XRD results. In addition, the Zn-fel(4)-LSH/U10 sample has a smaller amount of ferulate anions than the Zn-fel(4)-LSH material. However, the Zn-fel(4)-LSH/U10 material presents a high amount of water molecules in its chemical composition, which can be correlated to the relative intensity of the hydroxyl band observed in FTIR results. Again, it is verified that ultrasonic cavitation induces specific interactions between ferulate species, water molecules, and LSH layers, influencing on the quantity of water and organic anions adsorbed and/or intercalated. 
Table 3. Mass percentage ( $\mathrm{wt} \%$ ) attributed to water loss, ferulate decomposition, and residue formed by thermal decomposition of the Zn-fel(4)-LSH and Zn-fel(4)-LSH/U10 samples.

\begin{tabular}{cccc}
\hline Sample & $\mathbf{H}_{\mathbf{2}} \mathbf{O} / \mathbf{w t} \mathbf{\%}$ & Ferulate Anion/wt $\%$ & Residue/wt $\mathbf{o}$ \\
\hline Zn-fel(4)-LSH & 18 & 35 & 47 \\
Zn-fel(4)-LSH/U10 & 38 & 19 & 43 \\
\hline
\end{tabular}

The TGA curve of the Nafel salt (Figure A4) shows that thermal decomposition of this organic compound occurs in four main steps. The decomposition steps are observed in the following temperature range ( $\mathrm{wt} \%): 100-315^{\circ} \mathrm{C}(34 \%), 315-395^{\circ} \mathrm{C}(16 \%)$, $395-677^{\circ} \mathrm{C}(5.0 \%)$, and $677-900{ }^{\circ} \mathrm{C}(18 \%)$. The first step is related to water loss and partial decomposition of the sodium ferulate salt. Analyzing the temperature range of the initial decomposition of ferulate anions in the layered materials and Nafel salt, it is noted that the intercalation process provides the increase of the thermal stability of ferulate species. This increase of the thermal stability is associated to the confinement of ferulate anions in the interlayer region, which changes the oxidation mechanisms of organic species. Therefore, great thermal stability of intercalated ferulate anions is an advantageous aspect for use of the LSH-ferulate materials in photoprotective products.

The UV shielding performance of cosmetic formulations containing Zn-fel(4)-LSH and $\mathrm{Zn}-\mathrm{fel}(4)-\mathrm{LSH} / \mathrm{U} 10$ materials as active ingredients of the photoprotective products was analyzed by the in vitro sun protection factor (SPF) method. The in vitro SPF method is based on UV-VIS spectrophotometric measurements [51,52]; consequently, absorption spectra measurements of photoprotective creams films were realized (Figure A5) to obtain in vitro SPF values. A commercial sunscreen product (SPF labeled equal to 10) was used as a reference standard for assessing the reliability and consistency of the SPF results. Comparing the SPF labeled (SPF equal to 10) and the SPF experimental of the commercial sunscreen (Table 4), it is verified that the SPF values are close, indicating that the in vitro method used allows the evaluation of the UV shielding capacity of cosmetic formulations.

Table 4. In vitro SPF values of commercial sunscreen product, base, $\mathrm{Zn}-\mathrm{NO}_{3}-\mathrm{LSH}$, Zn-fel(4)-LSH/U10, Nafel/1, Zn-fel(4)-LSH, and Nafel/2 creams.

\begin{tabular}{cccc}
\hline Formulation & SPF & Standard Deviation & Confidence Interval-95\% \\
\hline Commercial sunscreen * & 8.6 & 2.4 & 3.8 \\
Base & 2.3 & 0.4 & 0.7 \\
Zn-NO -LSH $_{3}$ & 7.8 & 0.7 & 1.1 \\
Zn-fel(4)-LSH/U10 & 8.0 & 1.5 & 2.3 \\
Nafel/1 & 6.8 & 0.7 & 1.2 \\
Zn-fel(4)-LSH & 12.1 & 0.9 & 1.4 \\
Nafel/2 & 7.0 & 1.1 & 1.8 \\
\hline
\end{tabular}

${ }^{*}$ Commercial sunscreen product that has SPF labeled equal to 10.

In order to facilitate the identification of the cosmetic formulations, the skin care formulation without active ingredients was designated base cream and other formulations were named with the same acronyms of samples dispersed in the colloidal system. So, the formulation containing zinc hydroxide nitrate host matrix was named $\mathrm{Zn}-\mathrm{NO}_{3}-\mathrm{LSH}$ cream and formulations containing LSH-ferulate materials were designated Zn-fel(4)-LSH and $\mathrm{Zn}-\mathrm{fel}(4)-\mathrm{LSH} / \mathrm{U} 10$ creams. In addition, cosmetic formulations containing $0.1 \%$ and $1.8 \mathrm{wt} \%$ of the sodium ferulate salt were named Nafel/1 and Nafel/2 creams, respectively. To compare UV shielding ability of the LSH-ferulate materials and ferulate species isolated, $\mathrm{Nafel} / 1$ and Nafel/ 2 cream formulations have the same amount of ferulate anions present in the chemical composition of $\mathrm{Zn}$-fel(4)-LSH/U10 and Zn-fel(4)-LSH samples, respectively.

The Zn- $\mathrm{NO}_{3}$-LSH, Zn-fel(4)-LSH/U10, Nafel/1, Zn-fel(4)-LSH, and Nafel/2 creams have higher SPF values than the base cream (Table 4) due to the colloidal dispersion of ferulate molecules or layered materials ( $\mathrm{Zn}-\mathrm{NO}_{3}-\mathrm{LSH}$ and $\mathrm{LSH}$-ferulate samples) in 
the cosmetic formulations. These compounds dispersed in the skin care cream have UV absorption capacity as seen in the UV-VIS absorption spectra (Figures 8 and 9). Based on the literature $[53,54]$, sunscreens that have SPF $\leq 15$ prevent damages to human skin caused by excessive exposure to UVB radiation; therefore, cosmetic formulations obtained present UVB protection.

The SPF values of $\mathrm{Zn}-\mathrm{NO}_{3}-\mathrm{LSH}, \mathrm{Zn}-\mathrm{fel}(4)-\mathrm{LSH} / \mathrm{U10}, \mathrm{Nafel} / 1$, and Nafel/2 creams are close to each other (Table 4), indicating a similar UV protection performance. However, higher SPF value of the Zn-fel(4)-LSH cream shows a better UV shielding performance, which demonstrates the potential of the $\mathrm{Zn}$-fel(4)-LSH material as active constituent of sunscreens. Therefore, synergistic effects from host-guest interactions between ferulate anions and LSH layers are responsible for high UV shielding ability of the Zn-fel(4)LSH material.

The smaller UV shielding capacity of the Zn-fel(4)-LSH/U10 cream when compared to the $\mathrm{Zn}$-fel(4)-LSH formulation can be related to the amount of ferulate anions present in the chemical composition and/or optical properties of the colloidal system resulting from intermolecular interactions between layered material particles and formulation constituents. Ultrasound cavitation causes surface modifications of the $\mathrm{Zn}$-fel(4)-LSH/U10 particles observed by zeta potential measurements (Figure 3) affecting the interfacial structuring in the colloidal system.

High concentrations of reactive oxygen species (ROS) combined to deficit of cellular defense mechanisms cause damages to the human organism [55], e.g., lipoperoxidation [56]. Thus, ROS effects can be minimized by antioxidant compounds [57]. In this perspective, materials that have UV shielding ability and antioxidant activity perform simultaneously beneficial functions to the human organism; consequently, they can be denominated multifunctional filters $[58,59]$. The antioxidant capacity of the $\mathrm{Zn}-\mathrm{NO}_{3}-\mathrm{LSH}, \mathrm{LSH}$-ferulate materials, and Nafel was investigated by spectrophotometric methods [57] using model radicals $\left(\mathrm{DPPH}^{\bullet}\right.$ and $\left.\mathrm{ABTS}^{\bullet+}\right)$ and radical $\left(\mathrm{ROO}^{\bullet}\right)$ and non-radical $(\mathrm{HOCl})$ reactive species of occurrence in biological systems. It is important to mention that the $\mathrm{Zn}-\mathrm{NO}_{3}$ - $\mathrm{LSH}$ host matrix does not present antioxidant activity against to reactive species investigated in this work (Figures A6 and A7).

The $\mathrm{DPPH}^{\bullet}$ is a free radical that has an unpaired electron in the nitrogen atom that is conjugated to the aromatic ring [60]. This reactive species shows a UV-VIS absorption band with maximum value at $517 \mathrm{~nm}$ [60]. Redox reactions between DPPH ${ }^{\bullet}$ radicals and antioxidant compounds cause the reduction of $\mathrm{DPPH}^{\bullet}$ species, providing the intensity decrease of absorption band at $517 \mathrm{~nm}$. Thus, antioxidant capacity of analyzed compounds is directly related to intensity of this characteristic absorption band of DPPH ${ }^{\bullet}$. The linear relationship between concentration of the antioxidant compound and capture percentage of $\mathrm{DPPH}^{\bullet}$ species allows to calculate the effective concentration $\left(\mathrm{EC}_{50}\right)$ of the antioxidant sample needed to capture $50 \%$ of the radicals present in the solution through the equation obtained by linear regression. The $\mathrm{EC}_{50}$ parameter in percentage is ordinarily used to compare the antioxidant activity of different chemical compounds [57].

Analyzing the results of the DPPH assay (Figure 11), it is verified that Nafel salt and LSH-ferulate materials have DPPH ${ }^{\bullet}$ capturing ability due to the increase of the percentage capture of these reactive species with the concentration increase of these antioxidant compounds. The $\mathrm{EC}_{50}$ values obtained for $\mathrm{Zn}$-fel(4)-LSH, Zn-fel(4)-LSH/U10, and Nafel compounds are $0.0882,0.0957$, and $1.34 \mathrm{mg} \mathrm{mL}^{-1}$, respectively. Therefore, the following increasing order in DPPH ${ }^{\bullet}$ capture efficiency is observed: Nafel $<\mathrm{Zn}$-fel(4)-LSH/U10 < $\mathrm{Zn}$-fel(4)-LSH. This $\mathrm{DPPH}^{\bullet}$ capture efficiency of LSH-ferulate materials indicates their potential as multifunctional filters.

Similar to the $\mathrm{DPPH}^{\bullet}$ assay, the method of $\mathrm{ABTS}^{\bullet+}$ cation capture is based on oxidationreduction reactions analyzed by UV-VIS spectrophotometric measurements [57]. In this method, the intensity decrease of the absorption band of ABTS ${ }^{\bullet+}$ species at $734 \mathrm{~nm}$ is proportional to the antioxidant concentration increase [61]. Again, the $\mathrm{EC}_{50}$ parameter is used to express antioxidant capacity. The results of the $\mathrm{ABTS}^{\bullet+}$ test (Figure 12) show 
that Nafel salt and LSH-ferulate materials present $\mathrm{ABTS}^{\bullet+}$ scavenging activity. The $\mathrm{EC}_{50}$ values of Zn-fel(4)-LSH, Zn-fel(4)-LSH/U10, and Nafel samples are 0.00615, 0.00504, and $0.00101 \mathrm{mg} \mathrm{mL}^{-1}$, respectively; thus, the increasing order in efficiency for capturing the $\mathrm{ABTS}^{\bullet+}$ species is Zn-fel(4)-LSH $<\mathrm{Zn}$-fel(4)-LSH/U10 $<$ Nafel, the inverse capture efficiency order of the $\mathrm{DPPH}^{\bullet}$ assay.

Hypochlorous acid $(\mathrm{HOCl})$ is a non-radical reactive species, which has strong antimicrobial activity in the human organism [62]. However, high reactivity of the $\mathrm{HOCl}$ combined to propensity to permeate membranes can oxidize biomolecules causing cellular damages [62]. In the hypochlorous acid scavenging assay, the antioxidant compound interacts with $\mathrm{HOCl} / \mathrm{OCl}^{-}$species and prevents the formation of the blue chromophore compound produced by oxidation of the TMB [63]. Thus, the intensity decrease of the absorption band of blue chromophore at $655 \mathrm{~nm}$ is proportional to the increase of the antioxidant concentration. Based on the results of this assay (Figure 13), it is noted that LSH-ferulate materials and Nafel salt have $\mathrm{HOCl} / \mathrm{OCl}^{-}$inhibiting capacity and the increasing order in efficiency for capturing $\mathrm{HOCl} / \mathrm{OCl}^{-}$species is $\mathrm{Zn}$-fel(4)-LSH/U10 $\left(\mathrm{EC}_{50}=0.00319 \mathrm{mg} \mathrm{mL} \mathrm{mL}^{-1}\right)<$ $\mathrm{Zn}$-fel(4)-LSH $\left(\mathrm{EC}_{50}=0.00297 \mathrm{mg} \mathrm{mL}^{-1}\right)<$ Nafel $\left(\mathrm{EC}_{50}=0.000827 \mathrm{mg} \mathrm{mL}^{-1}\right)$. Therefore, LSH-ferulate materials and Nafel salt act as $\mathrm{HOCl} / \mathrm{OCl}^{-}$sequestrants and can reduce tissue damages caused by attacks of microorganisms and inflammatory processes [57].

The $\mathrm{ROO}^{\bullet}$ is a radical reactive species and is produced by the lipoperoxidation process (LPO) [63]. Among experimental methods used to investigate the inhibition of the LPO mechanism, Crocin bleaching assay is suitable to evaluate the antioxidant activity against $\mathrm{ROO}^{\bullet}$ radicals $[57,63]$. This assay is based on the bleaching rate of the crocin solution in the presence of antioxidants; therefore, the $\mathrm{ROO}^{\bullet}$ capturing ability depends on kinetic competition between crocin and antioxidant compounds. The ROO ${ }^{\bullet}$ scavenging activity is directly related to the angular coefficient obtained by linear regression from $V_{0} / \mathrm{V}$ versus [Antioxidant]/[Crocin] graphs. Higher angular coefficient values indicate higher antioxidant activity of samples. The results of the Crocin bleaching assay (Figures 14 and A8) show that samples exhibit $\mathrm{ROO}^{\bullet}$ scavenging activity; therefore, LSH-ferulate materials have potential to reduce the LPO of cellular membranes. According to slope and $\mathrm{EC}_{50}$ values of samples (Table 5), the increasing order of the antioxidant ability is: Zn-fel(4)-LSH/U10 $<$ Zn-fel(4)-LSH $<$ Nafel.

The reactive species assays realized show that Zn-fel(4)-LSH and Zn-fel(4)-LSH/U10 materials have capacity to capture $\mathrm{DPPH}{ }^{\bullet}, \mathrm{ABTS}^{\bullet+}, \mathrm{ROO}^{\bullet}$, and $\mathrm{HOCl} / \mathrm{OCl}^{-}$reactive species. This antioxidant behavior indicates that LSH-ferulate materials cause decrease and/or inhibition of reactive species probably through to redox reactions with ferulate anions present in the chemical composition of these layered materials and/or interactions between LSH layers and reactive species. The Zn-fel(4)-LSH material exhibits a better $\mathrm{DPPH}^{\bullet}, \mathrm{ROO}^{\bullet}$, and $\mathrm{HOCl} / \mathrm{OCl}^{-}$scavenging activity than the $\mathrm{Zn}$-fel(4)-LSH/U10 sample, which can be related to a greater amount of ferulate anions in its composition as seen in TGA/DSC results (Table 3). In the ABTS ${ }^{\bullet+}$ assay, inverse order in efficiency for capturing the reactive species can be correlated to unpaired electron distribution in the $\pi$-system and/or positive charge of the $\mathrm{ABTS}^{\bullet+}$ radicals. Therefore, antioxidant and UV shielding abilities exhibited by LSH-ferulate materials confirm their potential as multifunctional filters, mainly the Zn-fel(4)-LSH material.

Table 5. $\mathrm{DPPH}^{\bullet}, \mathrm{ABTS}^{\bullet+}, \mathrm{HOCl} / \mathrm{OCl}^{-}$, and $\mathrm{ROO}^{\bullet}$ scavenging activities of $\mathrm{Nafel}\left(\mathrm{NaC}_{10} \mathrm{H}_{9} \mathrm{O}_{4}\right), \mathrm{Zn}$-fel(4)-LSH and $\mathrm{Zn}$-fel(4)$\mathrm{LSH} / \mathrm{U} 10$ samples expressed in the $\mathrm{EC}_{50}$ values and linear regression slopes for the $\mathrm{V}_{0} / \mathrm{V}$ versus [Antioxidant]/[Crocin] graphs.

\begin{tabular}{|c|c|c|c|c|c|}
\hline Sample & $\begin{array}{c}\mathrm{DPPH}^{\bullet} \\
\mathrm{EC}_{50} / \mathrm{mg} \mathrm{mL}^{-1}\end{array}$ & $\begin{array}{c}\mathrm{ABTS}^{\bullet+} \\
\mathrm{EC}_{50} / \mathrm{mg} \mathrm{mL}^{-1}\end{array}$ & $\begin{array}{c}\mathrm{HOCl} / \mathrm{OCl}^{-} \\
\mathrm{EC}_{50} / \mathrm{mg} \mathrm{mL}^{-1}\end{array}$ & $\begin{array}{c}\mathrm{ROO}^{\bullet} \\
\mathrm{EC}_{50} / \mathrm{mg} \mathrm{mL}^{-1}\end{array}$ & Slope \\
\hline Nafel & 1.34 & 0.00101 & 0.000827 & 0.00615 & 4.93 \\
\hline Zn-fel(4)-LSH & 0.0882 & 0.00615 & 0.00297 & 0.170 & 0.26 \\
\hline Zn-fel(4)-LSH/U10 & 0.0957 & 0.00504 & 0.00319 & 0.209 & 0.16 \\
\hline
\end{tabular}



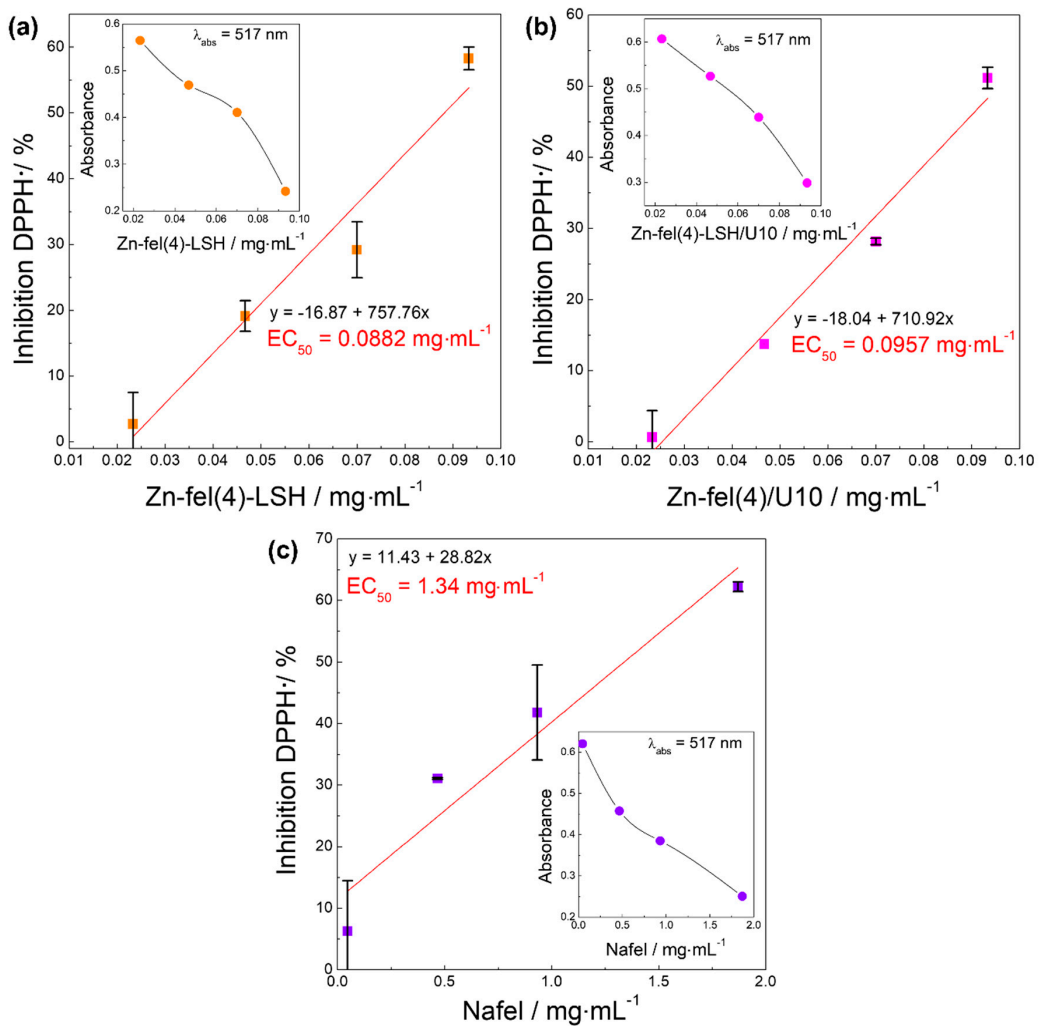

Figure 11. Inhibition (capture) of DPPH ${ }^{\bullet}$ radicals by (a) Zn-fel(4)-LSH, (b) Zn-fel(4)-LSH/U10, and (c) Nafel $\left(\mathrm{NaC}_{10} \mathrm{H}_{9} \mathrm{O}_{4}\right)$ samples. Figures inserted show average absorbance of DPPH${ }^{\bullet}$ species as function of the sample concentration.
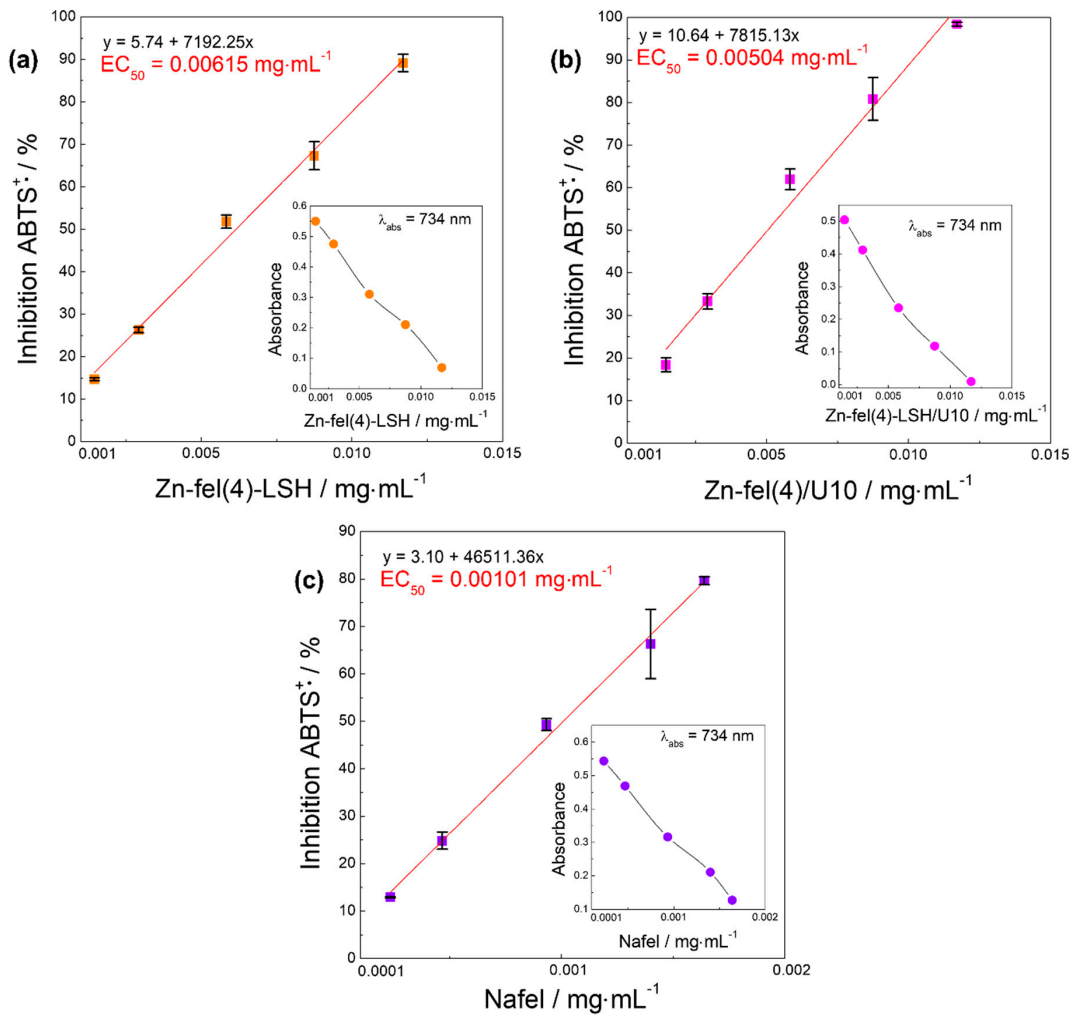

Figure 12. Inhibition (capture) of $\mathrm{ABTS}^{\bullet+}$ radicals by (a) Zn-fel(4)-LSH, (b) Zn-fel(4)-LSH/U10, and (c) Nafel $\left(\mathrm{NaC}_{10} \mathrm{H}_{9} \mathrm{O}_{4}\right)$ samples. Figures inserted show average absorbance of $\mathrm{ABTS}^{\bullet+}$ species as function of the sample concentration. 

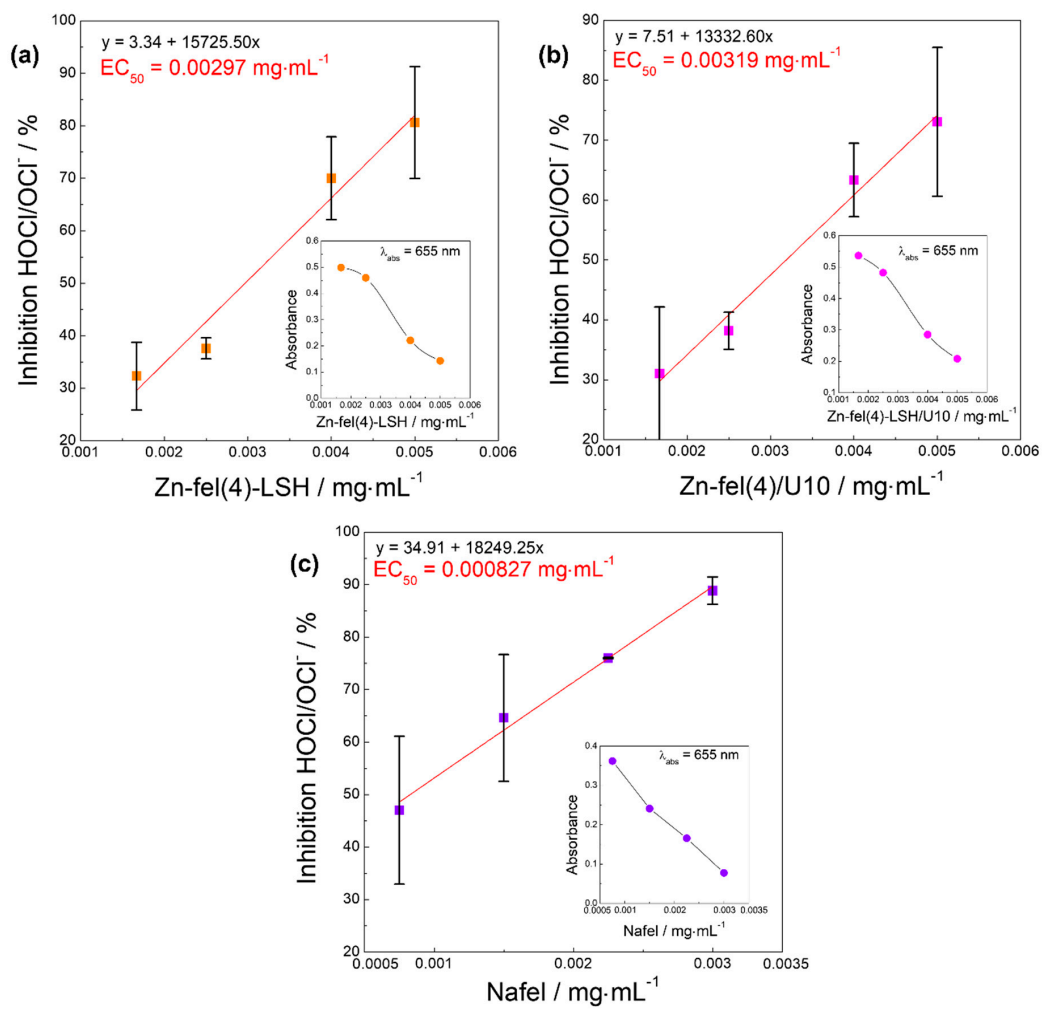

Figure 13. Inhibition (capture) of $\mathrm{HOCl} / \mathrm{OCl}^{-}$reactive species by (a) $\mathrm{Zn}$-fel(4)-LSH, (b) Zn-fel(4)$\mathrm{LSH} / \mathrm{U} 10$ and (c) Nafel $\left(\mathrm{NaC}_{10} \mathrm{H}_{9} \mathrm{O}_{4}\right)$ samples. Figures inserted show average absorbance of the $\mathrm{TMB}$ chromophore in presence of $\mathrm{HOCl} / \mathrm{OCl}^{-}$species as function of sample concentration.

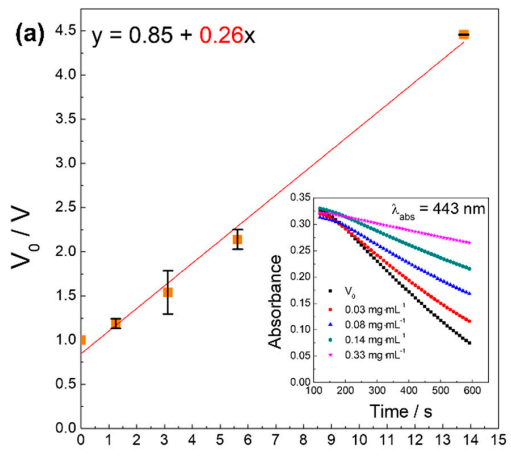

[Zn-fel(4)-LSH] / Crocin

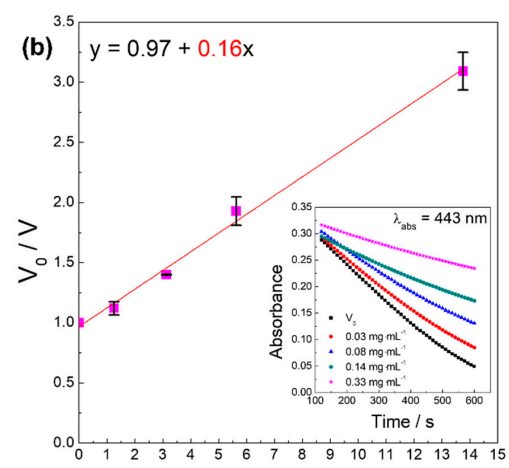

[Zn-fel(4)-LSH/U10]/ [Crocin]

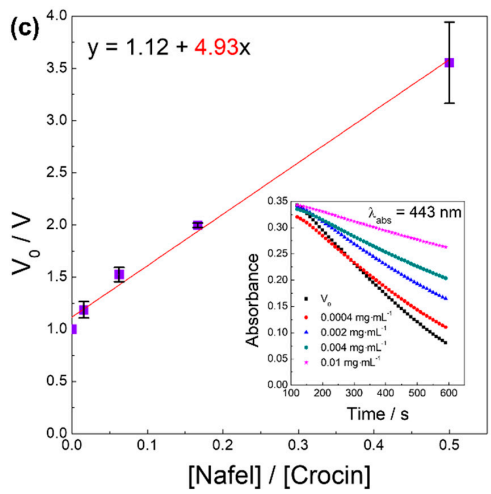

Figure 14. Representation between velocities and concentrations of (a) Zn-fel(4)-LSH, (b) Zn-fel(4)$\mathrm{LSH} / \mathrm{U10}$, and (c) Nafel $\left(\mathrm{NaC}_{10} \mathrm{H}_{9} \mathrm{O}_{4}\right)$ samples in the crocin bleaching assay. $\mathrm{V}_{0}$, velocity in the absence of LSH-ferulate materials and Nafel salt; V, velocity in the presence of LSH-ferulate materials and Nafel salt. 


\section{Materials and Methods}

\subsection{Materials}

For the synthesis of layered materials, zinc nitrate hexahydrate $\left(\mathrm{Zn}\left(\mathrm{NO}_{3}\right)_{2} \cdot 6 \mathrm{H}_{2} \mathrm{O}-\right.$ 99.98\%, Synth, Diadema, Brazil), ferulic acid $\left(\mathrm{C}_{10} \mathrm{H}_{10} \mathrm{O}_{4}-99.99 \%\right.$, Sigma-Aldrich, St. Louis, MO, USA), and sodium hydroxide ( $\mathrm{NaOH}-98.67 \%$, Synth) were used without further purification. The sodium ferulate salt $\left(\mathrm{NaC}_{10} \mathrm{H}_{9} \mathrm{O}_{4}\right)$ was obtained by mixing $\mathrm{C}_{10} \mathrm{H}_{10} \mathrm{O}_{4}$ and $\mathrm{NaOH}$, at a 1:1 molar ratio, in a mixed solution of ethanol and water. In the preparation of cosmetic formulations, dipropan-2-yl hexanedioate (Dhaymers, Taboão da Serra, Brazil), 2,3-dihydroxypropyl octadecanoate (Via Farma, São Paulo, Brazil), mixture of hexadecan-1-ol and octadecan-1-ol (Cetostearyl alcohol, Via Farma), mixture of hexadecan-1-ol, octadecan-1-ol, and oxirane (Cosmowax ${ }^{\circledR} \mathrm{J}$, Croda, Campinas, Brazil), (1-decanoyloxy-3-octanoyloxypropan-2-yl) dodecanoate (Via Farma), propane-1,2-diol (Qhemis, Jundiaí, Brazil), methyl 4-hydroxybenzoate (Synth), propyl 4-hydroxybenzoate (Synth), 2,2',2",2"'-(1,2-Ethanediyldinitrilo)tetraacetic acid (Qhemis) were used without further purification. The chemical compounds used in the reactive species scavenging assays were di(phenyl)-(2,4,6-trinitrophenyl)iminoazanium ( $\mathrm{DPPH}^{\bullet}$, Sigma-Aldrich), methanol (Synth), 2,2'-azino-bis(3-ethylbenzthiazoline-6-sulfonic acid) radicals (ABTS ${ }^{\bullet+}$, SigmaAldrich), potassium persulfate $\left(\mathrm{K}_{2} \mathrm{~S}_{2} \mathrm{O}_{8}\right.$, Sigma-Aldrich), ethanol, sodium hypochlorite (NaOCl, Sigma-Aldrich), 3,3',5,5'-tetramethyl[1,1'-biphenyl]-4,4'-diamine (TMB-SigmaAldrich), N,N-dimethylformamide (Synth), potassium iodide (Merck, Darmstadt, Germany), acetic acid (Merck), crocin (Sigma-Aldrich), 2,2'-azobis(2-amidinopropane) dihydrochloride (AAPH—Sigma-Aldrich) and dimethyl sulfoxide (Synth).

\subsection{Synthesis of Layered Zinc Hydroxide Nitrate Matrix}

The layered host matrix $\left(\mathrm{Zn}-\mathrm{NO}_{3}-\mathrm{LSH}\right)$ was prepared by the precipitation method [25]. A solution of $\mathrm{NaOH}\left(1.0 \mathrm{~mol} \mathrm{~L}^{-1}\right)$ was slowly added to a zinc nitrate solution containing $1.75 \cdot 10^{-2} \mathrm{~mol} \mathrm{~L}^{-1}$ of $\mathrm{Zn}^{2+}$ ions under nitrogen atmosphere and magnetic stirring, until the final $\mathrm{pH}$ adjusted to 6.5. The suspension was kept under magnetic stirring and nitrogen atmosphere during $3 \mathrm{~h}$. The solid obtained was filtered, washed with deionized water, and dried in presence of silica at room temperature for $24 \mathrm{~h}$.

\subsection{Synthesis of LSH Intercalated with Ferulate Anions}

The LSH-ferulate materials were synthetized by the anion exchange method $[23,26]$ and/or precipitation method at constant $\mathrm{pH}[25,26]$. In the anion exchange method, the $\mathrm{Zn}-\mathrm{NO}_{3}$ - $\mathrm{LSH}$ matrix was dispersed in a solution of the sodium ferulate salt $\left(\mathrm{C}_{10} \mathrm{H}_{9} \mathrm{O}_{4}{ }^{-} / \mathrm{Zn}\right.$ $\mathrm{NO}_{3}$-LSH molar ratio equal to 23.5) and the suspension obtained had the final $\mathrm{pH}$ adjusted to 7 with addition of a $1.0 \mathrm{~mol} \mathrm{~L}^{-1}$ solution of $\mathrm{NaOH}$. The suspension was subjected to magnetic stirring at room temperature for 5 days. The solid obtained was filtered, washed with deionized water and ethanol, and dried in presence of silica at room temperature for $24 \mathrm{~h}$.

For LSH intercalated with ferulate anions obtained by the precipitation method at constant $\mathrm{pH}$, a zinc nitrate solution was added slowly and under magnetic stirring to a solution of sodium ferulate salt $\left(\mathrm{Zn}^{2+} / \mathrm{C}_{10} \mathrm{H}_{9} \mathrm{O}_{4}{ }^{-}\right.$molar ratio equal to 3,4 , or 5) under nitrogen atmosphere. The solution $\mathrm{pH}$ was adjusted to 7 by the addition of a $1.0 \mathrm{~mol} \mathrm{~L}^{-1}$ solution of $\mathrm{NaOH}$. The suspension obtained was kept under magnetic stirring for 3 days and subjected or not to ultrasound treatment (Unique ${ }^{\circledR}$ ultrasonic cell disruptor, model DES500, ultrasound power of the $250 \mathrm{~W}$ ) for 10,20 , or $30 \mathrm{~min}$. The precipitated was filtered, washed with deionized water and ethanol, and dried in presence of silica at room temperature for $24 \mathrm{~h}$.

\subsection{Preparation of Cosmetic Formulations}

The cosmetic formulations were prepared by the colloidal dispersion of Nafel salt, Zn$\mathrm{NO}_{3}$-LSH matrix or LSH-ferulate materials (Zn-fel(4)-LSH and Zn-fel(4)-LSH/U10 samples) in the oil phase of the skin care formulation described by Saito et al. [11]. The oil/water- 
type dispersions were subjected to magnetic stirring for $1 \mathrm{~h}$ to cream formation. The mass percentage of formulation ingredients and the cosmetic creams obtained are shown in Table 6.

Table 6. Mass percentage of formulation ingredients of cosmetic creams containing $\mathrm{Zn}-\mathrm{NO}_{3}-\mathrm{LSH}, \mathrm{Zn}-\mathrm{fel}(4)-\mathrm{LSH}, \mathrm{Zn}-\mathrm{fel}(4)-$ $\mathrm{LSH} / \mathrm{U} 10$, or Nafel $\left(\mathrm{NaC}_{10} \mathrm{H}_{9} \mathrm{O}_{4}\right)$ compound.

\begin{tabular}{|c|c|c|c|c|c|c|c|}
\hline \multirow{2}{*}{$\begin{array}{c}\text { Ingredients } \\
\text { Cetostearyl alcohol }\end{array}$} & \multirow{2}{*}{$\begin{array}{c}\text { Phase } \\
\text { Oil }\end{array}$} & \multicolumn{6}{|c|}{ Cosmetic Formulations/\% } \\
\hline & & 2.00 & 2.00 & 2.00 & 2.00 & 2.00 & 2.00 \\
\hline 2,3-dihydroxypropyl octadecenoate & Oil & 2.00 & 2.00 & 2.00 & 2.00 & 2.00 & 2.00 \\
\hline Cosmowax ${ }^{\circledR} \mathrm{J}$. & Oil & 8.00 & 8.00 & 8.00 & 8.00 & 8.00 & 8.00 \\
\hline Dipropan-2-yl hexanedioate & Oil & 1.50 & 1.50 & 1.50 & 1.50 & 1.50 & 1.50 \\
\hline (1-decanoyloxy-3-octanoyloxypropan-2-yl)dodecanoate & Oil & 1.50 & 1.50 & 1.50 & 1.50 & 1.50 & 1.50 \\
\hline $\mathrm{Zn}-\mathrm{NO}_{3}-\mathrm{LSH}$ & Oil & - & 5.00 & - & - & - & - \\
\hline $\mathrm{Zn}-\mathrm{fel}(4)-\mathrm{LSH}$ & Oil & - & - & 5.00 & - & - & - \\
\hline Zn-fel(4)-LSH/U10 & Oil & - & - & - & 5.00 & - & - \\
\hline Nafel & Oil & - & - & - & - & 1.8 & 0.1 \\
\hline Propane-1,2-diol & Aqueous & 4.00 & 4.00 & 4.00 & 4.00 & 4.00 & 4.00 \\
\hline Methyl 4-hydroxybenzoate & Aqueous & 0.18 & 0.18 & 0.18 & 0.18 & 0.18 & 0.18 \\
\hline Propyl 4-hydroxybenzoate & Aqueous & 0.02 & 0.02 & 0.02 & 0.02 & 0.02 & 0.02 \\
\hline $2,2^{\prime}, 2^{\prime \prime}, 2^{\prime \prime \prime}-(1,2-E t h a n e d i y l d i n i t r i l o)$ tetraacetic acid & Aqueous & 0.05 & 0.05 & 0.05 & 0.05 & 0.05 & 0.05 \\
\hline Distilled Water & Aqueous & 80.75 & 75.75 & 75.75 & 75.75 & 78.95 & 80.65 \\
\hline
\end{tabular}

\subsection{Characterization Techniques}

X-ray diffraction (XRD) patterns of powdered samples were recorded on a Rigaku diffractometer, model RINT 2000, using $\mathrm{CuK} \alpha$ radiation $(1.5418 \AA$, $40 \mathrm{kV}, 70 \mathrm{~mA}$, scan $2 \theta$ range $3-70^{\circ}$, and scan speed $0.02^{\circ} / 10 \mathrm{~s}$ ) and Ni filter. Zeta potential measurements of layered materials dispersed in deionized water were collected in a Zetasizer Nano ZS analyzer (Malvern Instruments Ltd., Malvern, UK) using DTS 1070 cuvettes, dielectric constant equal to 78.5 , and refractive and absorption index adjusted to 1.5 and 0.01 , respectively. FTIR spectra were collected in the $4000-368 \mathrm{~cm}^{-1}$ region in a Bruker spectrophotometer, model FTIR Vertex70, using the ATR method. Color index was obtained in a Konica Minolta spectrophotometer, model CM-2500d, equipped with $\mathrm{d} / 8^{\circ}$ integrating sphere (CIELab color space). Diffuse reflectance spectra of powdered samples were recorded on a Perkin Elmer spectrophotometer, model LAMBDA 1050 UV-VIS-NIR, equipped with Spectralon $150 \mathrm{~nm}$ integrating sphere. Thermal analyses (TGA/DSC) of powered samples were recorded on a SQ600 thermoanalyzer (TA Instruments Inc. New Castle, USA) and a TGA 4000 thermoanalyzer (Perkin Elmer, Waltham, USA) using a heating rate of $10^{\circ} \mathrm{C} \mathrm{min}^{-1}$ and under synthetic air flow of $50 \mathrm{~mL} \mathrm{~min}^{-1}$.

\subsection{Molecular Modeling Method}

Molecular modeling of the ferulate anion was performed by semi-empirical calculations in the MOPAC2016 software, using the Sparkle/RM1 model with the keywords: BFGS, XYZ, SPARKLE, RM1, GNORM $=0.25$, PRECISE and CHARGE $=-1$.

\subsection{In Vitro Sun Protection Factor (SPF) Method}

The SPF values of cosmetic formulations were obtained from absorption spectra measurements using the in vitro sun protection factor assessment $[51,52,64]$, which is defined by:

$$
S P F=\frac{\int_{290}^{400} E(\lambda) S(\lambda) d \lambda}{\int_{290}^{400} E(\lambda) S(\lambda) T(\lambda) d \lambda},
$$

where $E(\lambda)$ is the erythema action spectrum and $S(\lambda)$ is the spectral irradiance of terrestrial sunlight under defined conditions by the International Organization for Standardization [65]. The $T(\lambda)$ corresponds to the optical diffuse transmittance of cosmetic formulations as a function of wavelength $(\lambda)$ and the wavelength integration limits refers to 
the combined UVB and UVA wavelength range. For the in vitro SPF assay, photoprotective films of cosmetic formulations were prepared by application of cosmetic creams on Transpore ${ }^{\circledR}$ tape, which is a UV-transparent substrate [64]. The spread amount of cosmetic formulation on the Transpore ${ }^{\circledR}$ substrate was $2.00 \pm 0.1 \mathrm{mg} \mathrm{cm}^{-2}$ using doctor blade technique [66]. Absorption spectra of photoprotective films were recorded on a Perkin Elmer spectrophotometer, model LAMBDA 465 UV-VIS-NIR. The in vitro SPF measurements were realized in quadruplicate and SPF results were expressed as mean \pm standard deviation \pm confidence interval (confidence level of the 95\%).

\subsection{In Vitro Antioxidant Activity Assays}

Spectrophotometric methods used to investigate the antioxidant activity of Nafel, $\mathrm{Zn}-\mathrm{NO}_{3}$-LSH matrix, and LSH-ferulate materials (Zn-fel(4)-LSH and Zn-fel(4)-LSH/U10 samples) were capture methods of di(phenyl)-(2,4,6-trinitrophenyl)iminoazanium ( $\mathrm{DPPH}^{\bullet}$ ) and 2,2'-azino-bis(3-ethylbenzthiazoline-6-sulfonic acid) $\left(\mathrm{ABTS}^{\bullet+}\right.$ ) radicals, hypochlorous acid $\left(\mathrm{HOCl} / \mathrm{OCl}^{-}\right)$scavenging assay and crocin bleaching assay. It is important to emphasize that these reactive species assays were realized in duplicate and capture (inhibition) percentage of reactive species was calculated from test results using the equation:

$$
I=\left(\frac{A_{0}-A_{c}}{A_{0}}\right),
$$

where $I$ is the capture (inhibition) percentage of reactive species, $A_{0}$ corresponds to absorbance of the chromophore compound in the absence antioxidant, and $A_{c}$ is the absorbance of the chromophore compound in presence of the antioxidant sample. The absorbance measurements were recorded on a microplate spectrophotometer (Biotek-Power Wave XS2, Winooski, VT, USA) and an OceanOptics USB 4000 for the tests with crocin, with magnetic stirring and Peltier heating.

\subsubsection{Method of $\mathrm{DPPH}^{\bullet}$ Radical Capture}

According to the methodology described by Soares et al. [67], DPPH assay is based on the absorbance monitoring of $\mathrm{DPPH}^{\bullet}$ radicals at $517 \mathrm{~nm}$, after incubation in the dark at $25^{\circ} \mathrm{C}$ for $20 \mathrm{~min}$, in the absence and presence of ethanolic solutions of samples. Inhibition percentage was calculated by average absorbance of $\mathrm{DPPH}^{\bullet}$ species as function of samples concentrations.

\subsubsection{ABTS Radical Cation Decolorization Assay}

The antioxidant activity of samples was assessed by ABTS ${ }^{\bullet+}$ radical cation decolorization assay described by Re et al. [68] with modifications. The $\mathrm{ABTS}^{\bullet+}$ radicals were produced by oxidation of the 2,2'-azino-bis(3-ethylbenzthiazoline-6-sulfonic acid) $\left(7.0 \times 10^{-3} \mathrm{~mol} \mathrm{~L}^{-1}\right)$ with $\mathrm{K}_{2} \mathrm{~S}_{2} \mathrm{O}_{8}$ oxidizing agent $\left(0.14 \mathrm{~mol} \mathrm{~L}^{-1}\right)$ in the absence of light at room temperature for $16 \mathrm{~h}$. The ABTS ${ }^{\bullet+}$ stock solution was diluted in sodium phosphate buffer $\left(0.01 \mathrm{~mol} \mathrm{~L}^{-1}\right.$ and $\mathrm{pH}=7.0$ ) to an absorbance of $0.750 \pm 0.020$, at $734 \mathrm{~nm}$. Different amounts of the sample were added to $\mathrm{ABTS}^{\bullet+}$ solution and the reaction mixtures were incubated for $15 \mathrm{~min}$ in the dark at room temperature. Absorbance values of these mixtures were monitored at $734 \mathrm{~nm}$ and inhibition percentage was calculated by average absorbance of $\mathrm{ABTS}^{\bullet+}$ species as function of samples concentrations.

\subsubsection{Hypochlorous Acid $\left(\mathrm{HOCl} / \mathrm{OCl}^{-}\right)$Scavenging Assay}

In this assay, antioxidant activity is directly associated to interactions between sample and $\mathrm{HOCl} / \mathrm{OCl}^{-}$species, which prevents the formation of the blue chromophore compound produced by oxidation of the 3,3',5,5'-tetramethyl[1,1'-biphenyl]-4,4'-diamine (TMB). This blue chromophore compound has maximum absorbance at $655 \mathrm{~nm}$ [57]. A standard solution of $\mathrm{OCl}^{-}$was prepared by dissolution of the $\mathrm{NaOCl}$ in a $\mathrm{NaOH}$ solution $\left(0.01 \mathrm{~mol} \mathrm{~L}^{-1}\right)$ and the concentration of this standard solution was obtained by its molar absorptivity coefficient $\left(\varepsilon=350 \mathrm{~L} \mathrm{~mol}^{-1} \mathrm{~cm}^{-1}\right.$ at $\left.292 \mathrm{~nm}\right)$ [69]. Various concentrations of 
samples in sodium phosphate buffer $\left(0.05 \mathrm{~mol} \mathrm{~L}^{-1}\right.$ and $\left.\mathrm{pH}=7.4\right)$ were incubated with $\mathrm{HOCl} / \mathrm{OCl}^{-}\left(3.0 \times 10^{-5} \mathrm{~mol} \mathrm{~L}{ }^{-1}\right)$ for $10 \mathrm{~min}$. TMB $\left(2.8 \times 10^{-3} \mathrm{~mol} \mathrm{~L}^{-1}\right.$ dissolved in $50 \% \mathrm{~N}, \mathrm{~N}$-dimethylformamide with $0.01 \mathrm{~mol} \mathrm{~L}^{-1}$ potassium iodide in $0.8 \mathrm{~mol} \mathrm{~L}^{-1}$ acetic acid) was then added and incubated for $5 \mathrm{~min}$ at room temperature in the dark and the absorbance were monitored at $655 \mathrm{~nm}$, as described by Dypbukt [70], with modifications. The assay without the sample was used as the control (100\% reaction) and the absorbance of the reaction medium without $\mathrm{HOCl}$ was used as a reading blank. The inhibition percentage was calculated by average absorbance of the TMB chromophore in presence of $\mathrm{HOCl} / \mathrm{OCl}^{-}$ species as function of sample concentrations.

\subsubsection{Crocin Bleaching Assay}

According to the methodology described by Tubaro et al. [71], crocin bleaching assay is based on the absorbance monitoring of the crocin at $443 \mathrm{~nm}$ for $10 \mathrm{~min}$ in a competitive kinetics procedure. The thermolysis reaction of the 2,2'-azobis(2-amidinopropane) dihydrochloride (AAPH) at $40^{\circ} \mathrm{C}$ produces peroxyl radicals (ROO') at a constant rate, an aerated medium [63]. Thus, a kinetic competition for capturing of $\mathrm{ROO}^{\bullet}$ species occurs between crocin and antioxidants; consequently, the inhibition depends on the ability of samples in capture of these radicals $[57,63]$. In this test, a crocin stock solution was prepared by dissolution of the crocin in dimethyl sulfoxide (DMSO) and its concentration was obtained by its molar absorptivity coefficient $\left(\varepsilon=13.726 \mathrm{~L} \mathrm{~mol}^{-1} \mathrm{~cm}^{-1}\right.$ at $\left.443 \mathrm{~nm}\right)$ [63]. The crocin solution $\left(2.5 \cdot \times 10^{-5} \mathrm{~mol} \mathrm{~L}^{-1}\right)$ and sample solutions with different concentrations were added in a sodium phosphate buffer $\left(0.12 \mathrm{~mol} \mathrm{~L}^{-1}\right.$ and $\left.\mathrm{pH}=7.0\right)$ resulting in a mixture solution. The thermolysis reaction was started by addition of the AAPH solution $\left(12.5 \cdot \times 10^{-3} \mathrm{~mol} \mathrm{~L}^{-1}\right)$ in the mixed solution under constant stirring at $40^{\circ} \mathrm{C}$. The rate of crocin bleaching (linear behavior after $100 \mathrm{~s}$ of the reaction) was monitored at $443 \mathrm{~nm}$ for $10 \mathrm{~min}$. In order to eliminate possible interference of the sample, a test without crocin was performed for each solute and used as blank reaction. The crocin bleaching rate $\left(V_{0}\right)$ decreases in the presence of an antioxidant compound due to kinetic competition between crocin and antioxidant for capture to $\mathrm{ROO}^{\bullet}$ radicals. Therefore, the new bleaching rate $(V)$ is given by:

$$
V=V_{0} \times \frac{k_{c}[C]}{k_{c}[C]+k_{A}[A]},
$$

where $V_{0}=k_{1}\left[\mathrm{ROO}^{\bullet}\right][C], k_{c}=k_{1}\left[\mathrm{ROO}^{\bullet}\right], k_{a}=k_{2}\left[\mathrm{ROO}^{\bullet}\right]$, [ROO $\left.{ }^{\bullet}\right]$ is a concentration of the peroxyl radical, $V_{0}$ corresponds to reaction between crocin and $\mathrm{ROO}^{\bullet}$ species, $k_{1}$ and $k_{2}$ are rate constants for the $\mathrm{ROO}^{\bullet}$ - crocin reaction and $\mathrm{ROO}^{\bullet}$ - sample reaction, $[C]$ is the crocin concentration, and $[A]$ is the sample concentration. The decrease of the crocin bleaching rate in the presence of an antioxidant can be described by:

$$
\frac{V_{0}}{V}=\frac{k_{c}[C]+k_{A}[A]}{k_{c}[C]}=1+\frac{k_{A}}{k_{c}} \times \frac{[A]}{[C]} .
$$

The $k_{A} / k_{c}$ constant value corresponds to the angular coefficient obtained by linear regression for $V_{0} / V$ versus $[A] /[C]$ graph and indicates the relative ability of an antioxidant to interact with $\mathrm{ROO}^{\bullet}$ radicals. By dividing the $k_{A} / k_{c}$ constant of the sample by $k_{A} / k_{c}$ constant of a standard antioxidant, such as Trolox, it is possible to obtain the ratio of these constants and relative antioxidant capacity of the analyzed compound $[57,63]$.

\section{Conclusions}

LSH-ferulate materials were successfully synthesized by the anion exchange method and precipitation method at constant $\mathrm{pH}$ varying $\mathrm{Zn}^{2+} / \mathrm{fel}^{-}$molar ratio and ultrasound treatment time. Structural characterization shows the formation of layered materials composed by a mixture of LSH intercalated with ferulate anions. The intercalation process of ferulate anions in the LSH-ferulate materials is proven by increase of the basal spacing noted in XRD patterns, presence and changes of characteristic vibrational bands of ferulate 
anion, and LSH host observed in the FTIR and modifications of UV-VIS absorption bands when compared to Nafel salt and the $\mathrm{Zn}-\mathrm{NO}_{3}-\mathrm{LSH}$ matrix. According to the interlayer spacing values of layered materials, ferulate anion dimensions, and host-guest interactions observed in the XRD, FTIR, and UV-VIS results, mono and/or bilayer arrangements of organic anions in the interlayer region are proposed. In addition, LSH-ferulate samples exhibit yellowish-white color that do not compromise their use in the cosmetic products.

The precipitation method at constant $\mathrm{pH}$ advantages the interactions of the ferulate anion in the LSH host. Nevertheless, the anion exchange method gives rise to a layered material with an excess amount of adsorbed ferulate anions as seen in the zeta potential and FTIR results. The cavitation effect produced by ultrasound treatment causes structural changes in the LSH-ferulate samples, which results in an emergence of LSH phases, modifications in vibrational and UV-VIS absorption bands, and different chemical composition observed in TGA/DSC results. Moreover, the intercalation of ferulate anions in the LSH host provides the increase of the thermal stability of these organic species.

UV-VIS absorption spectra and in vitro SPF values indicate that LSH-ferulate materials present UV shielding ability, mainly UVB protection. Moreover, reactive species assay results show that layered materials have capacity to capture $\mathrm{DPPH}^{\bullet}, \mathrm{ABTS}^{\bullet+}$, $\mathrm{ROO}^{\bullet}$, and $\mathrm{HOCl} / \mathrm{OCl}^{-}$reactive species, consequently, they have potential to reduce damages to the human organism caused by reactive species effects. Optical properties combined to antioxidant activity of LSH-ferulate samples provide simultaneous beneficial functions to the human organism. Therefore, LSH-ferulate materials have singular properties that allow their use as multifunctional filters.

Author Contributions: Synthesis and characterization of LSH compounds, G.P.S.; structural and spectroscopic analyses of LSH materials, G.P.S., M.R.D. and M.A.C.; antioxidant activity assays, A.C.L.M. and R.P.A.; antioxidant activity analyses, A.C.L.M., R.P.A. and I.L.B.; writing-original draft preparation, G.P.S.; writing-review and editing, G.P.S., M.R.D., M.A.C., R.P.A. and I.L.B.; supervision, M.R.D. and M.A.C.; project administration, M.R.D.; funding acquisition, M.R.D., M.A.C. and I.L.B. All authors have read and agreed to the published version of the manuscript.

Funding: This research was funded by CNPq, grant number 313029/2017-2, and institutional infrastructure financed by FAPESP and CAPES. The PhD fellowship of G.P.S. was funded by CAPES and undergraduate scholarship of A.C.L.M. was financed by CNPq/PIBIC.

Acknowledgments: The authors thank institutional infrastructure and technical support offered by Instituto de Química and Faculdade de Ciências Farmacêuticas, Universidade Estadual Paulista (Unesp), Araraquara.

Conflicts of Interest: The authors declare no conflict of interest.

Sample Availability: Samples of the layered compounds, Zn-NO 3 -LSH, Zn-fel-LSH/ A, Zn-fel(3)LSH, Zn-fel(4)-LSH, Zn-fel(5)-LSH, Zn-fel(4)-LSH/U10, Zn-fel(4)-LSH/U20 and Zn-fel(4)-LSH/U30, are available from the authors. 


\section{Appendix A}

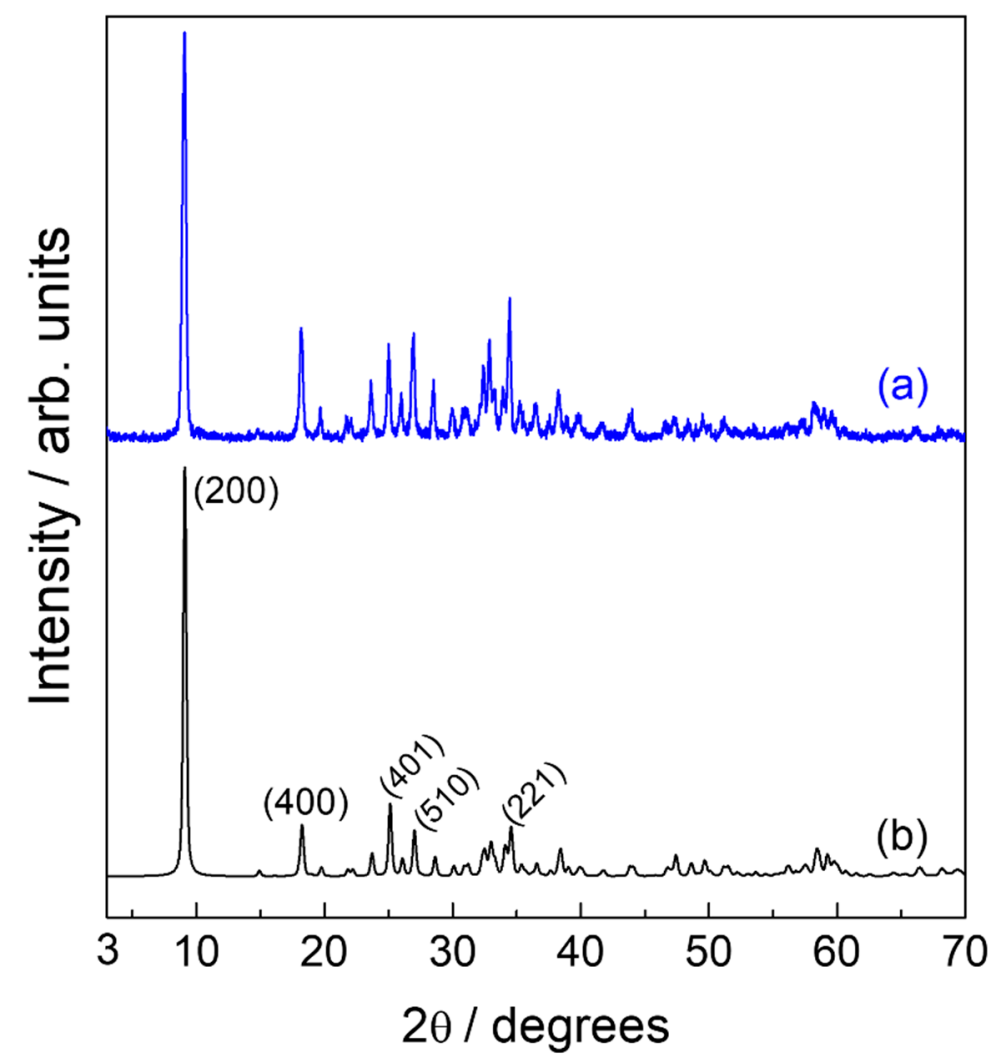

Figure A1. XRD pattern of the (a) Zn-NO $\mathrm{ZNSH}_{3}-\mathrm{LS}$ hst matrix and (b) JCPDS-PDF n $72-627$ card.

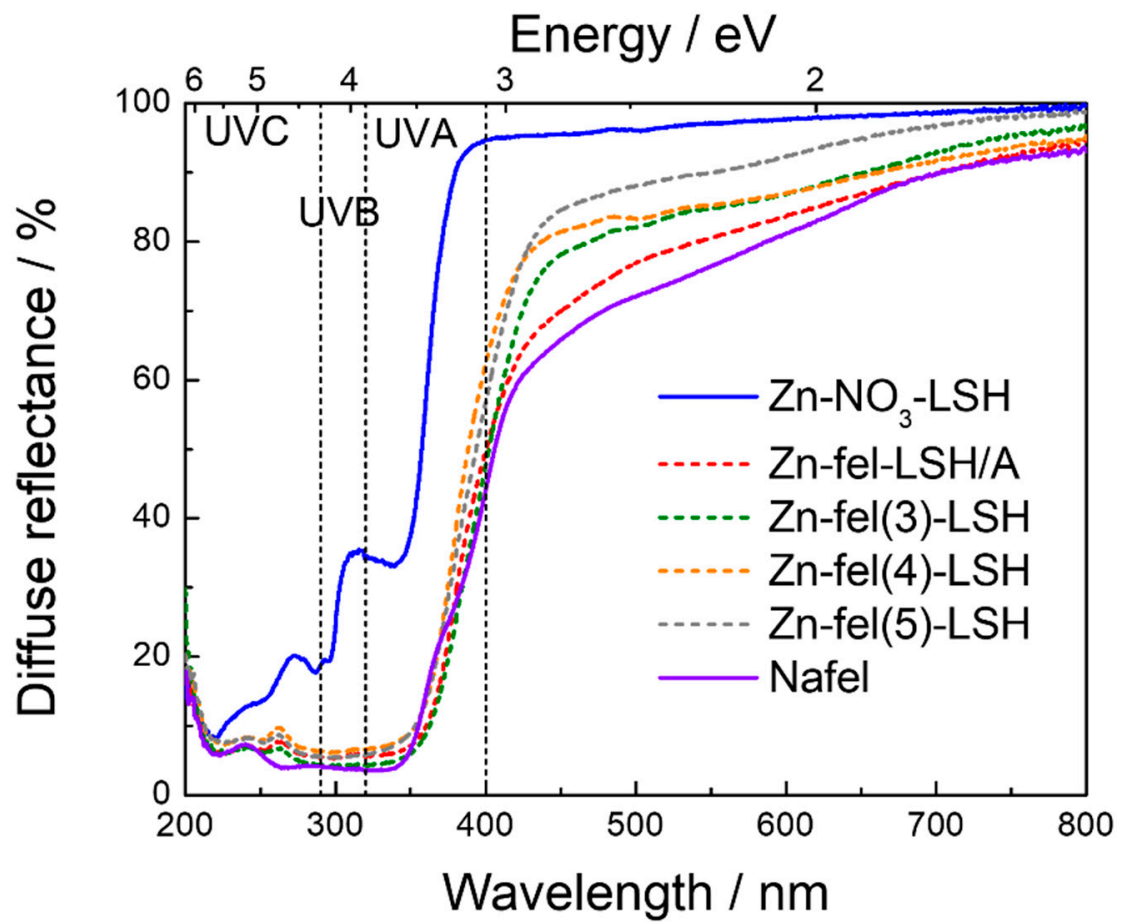

Figure A2. Diffuse reflectance spectra of Zn-NO 3 -LSH, Zn-fel-LSH/A, Zn-fel(3)-LSH, Zn-fel(4)-LSH, $\mathrm{Zn}$-fel(5)-LSH and Nafel $\left(\mathrm{NaC}_{10} \mathrm{H}_{9} \mathrm{O}_{4}\right)$ salt. 


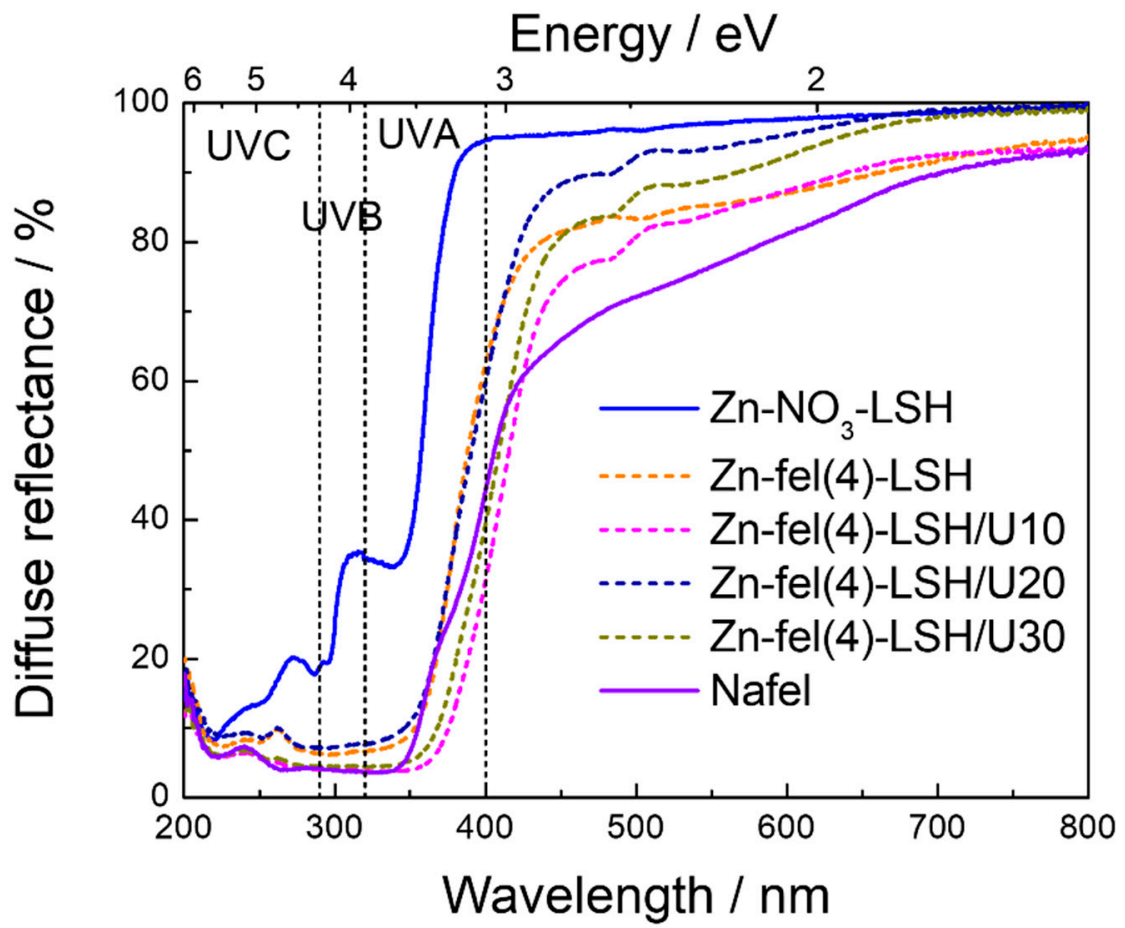

Figure A3. Diffuse reflectance spectra of $\mathrm{Zn}-\mathrm{NO}_{3}-\mathrm{LSH}$, Zn-fel(4)-LSH, Zn-fel(4)-LSH/U10, Zn-fel(4)$\mathrm{LSH} / \mathrm{U} 20, \mathrm{Zn}-\mathrm{fel}(4)-\mathrm{LSH} / \mathrm{U} 30$ and $\mathrm{Nafel}\left(\mathrm{NaC}_{10} \mathrm{H}_{9} \mathrm{O}_{4}\right)$ salt.

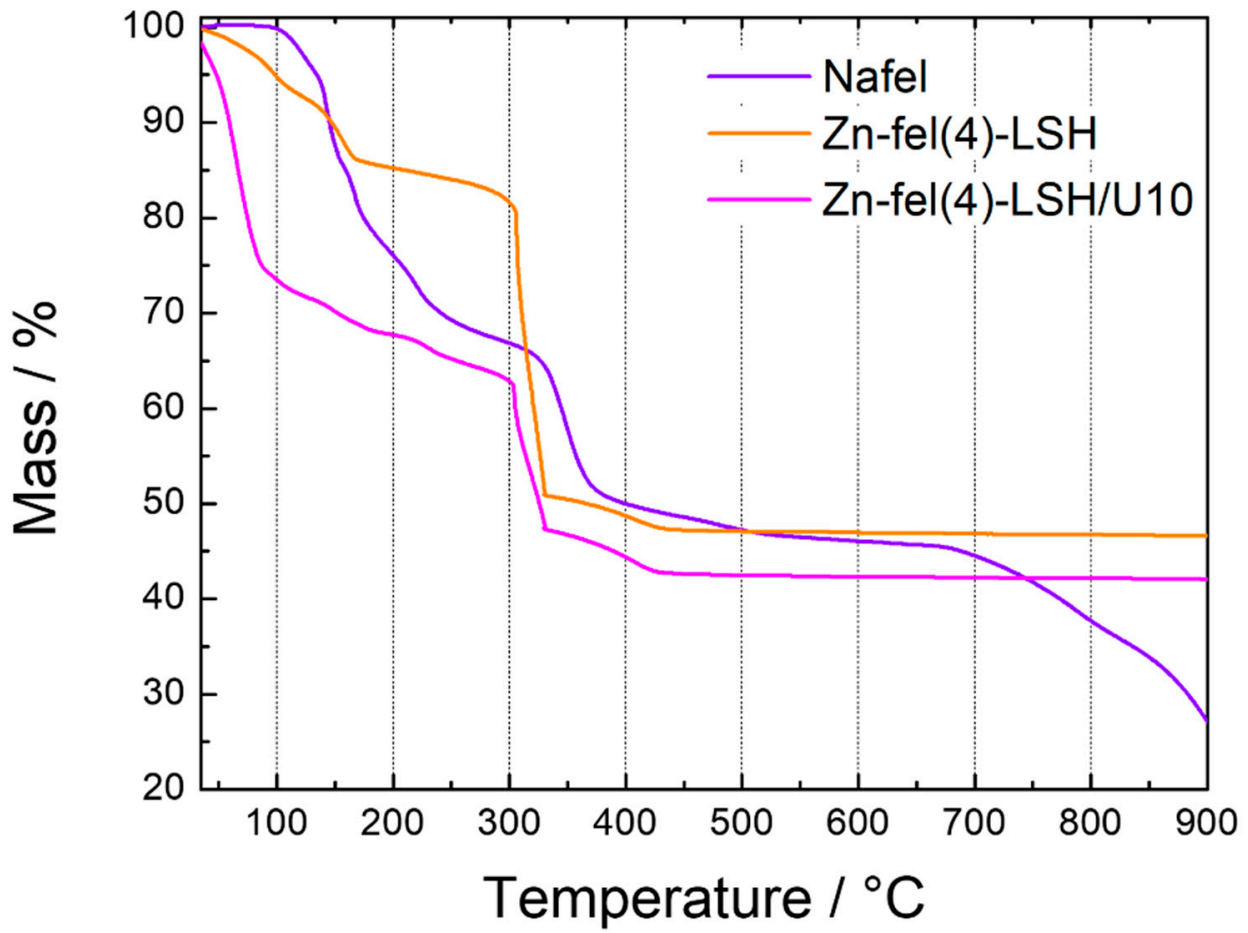

Figure A4. TGA curves of Nafel salt $\left(\mathrm{NaC}_{10} \mathrm{H}_{9} \mathrm{O}_{4}\right)$, $\mathrm{Zn}$-fel(4)-LSH and $\mathrm{Zn}$-fel(4)-LSH/U10 samples. 

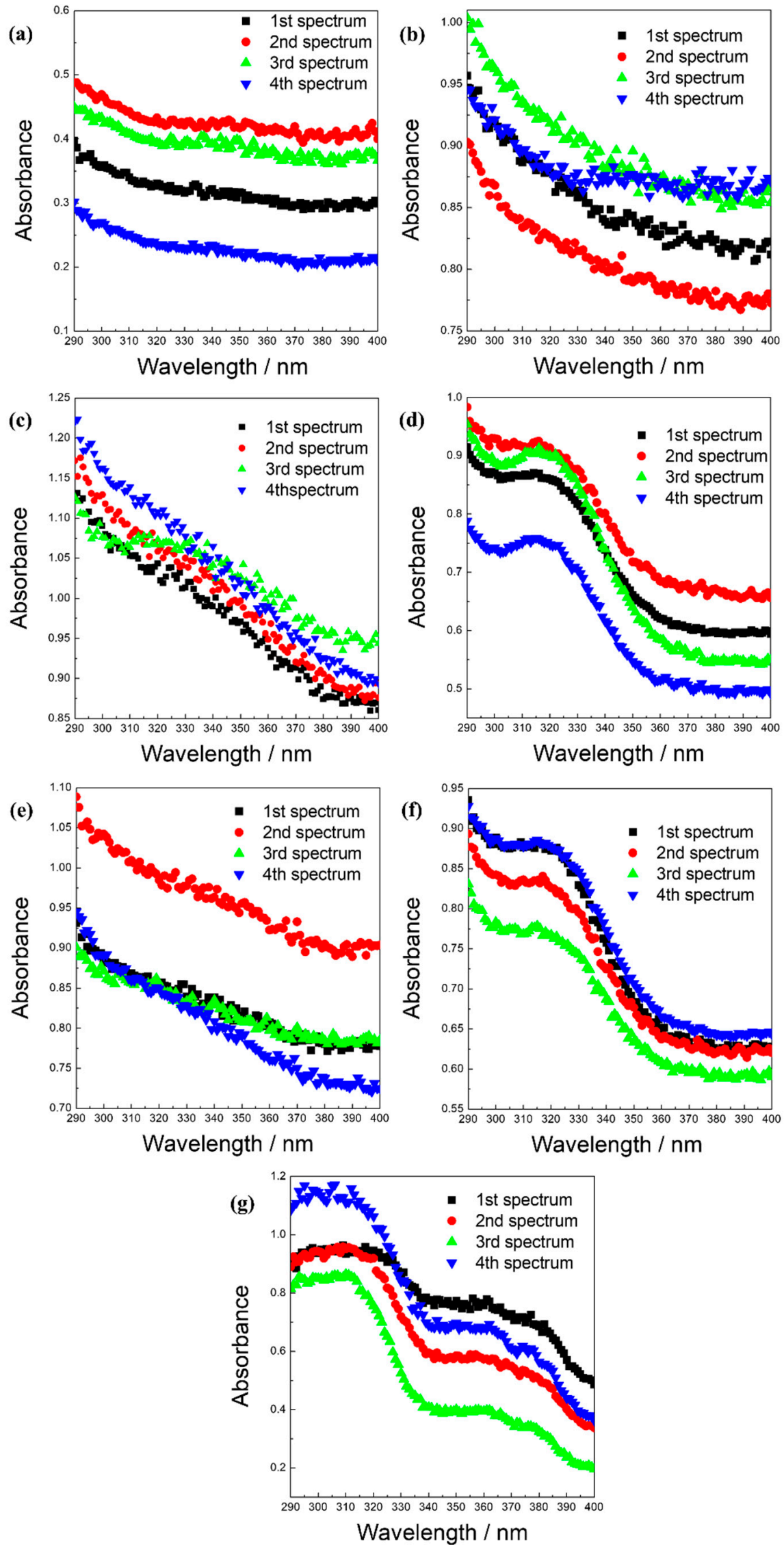

Figure A5. Absorption spectra measurements of (a) Base cream, (b) $\mathrm{Zn}-\mathrm{NO}_{3}-\mathrm{LSH}$ cream, (c) Zn-fel(4)LSH cream, (d) Nafel/2 cream, (e) Zn-fel(4)-LSH/U10 cream, (f) Nafel/1 cream and (g) commercial sunscreen films. 

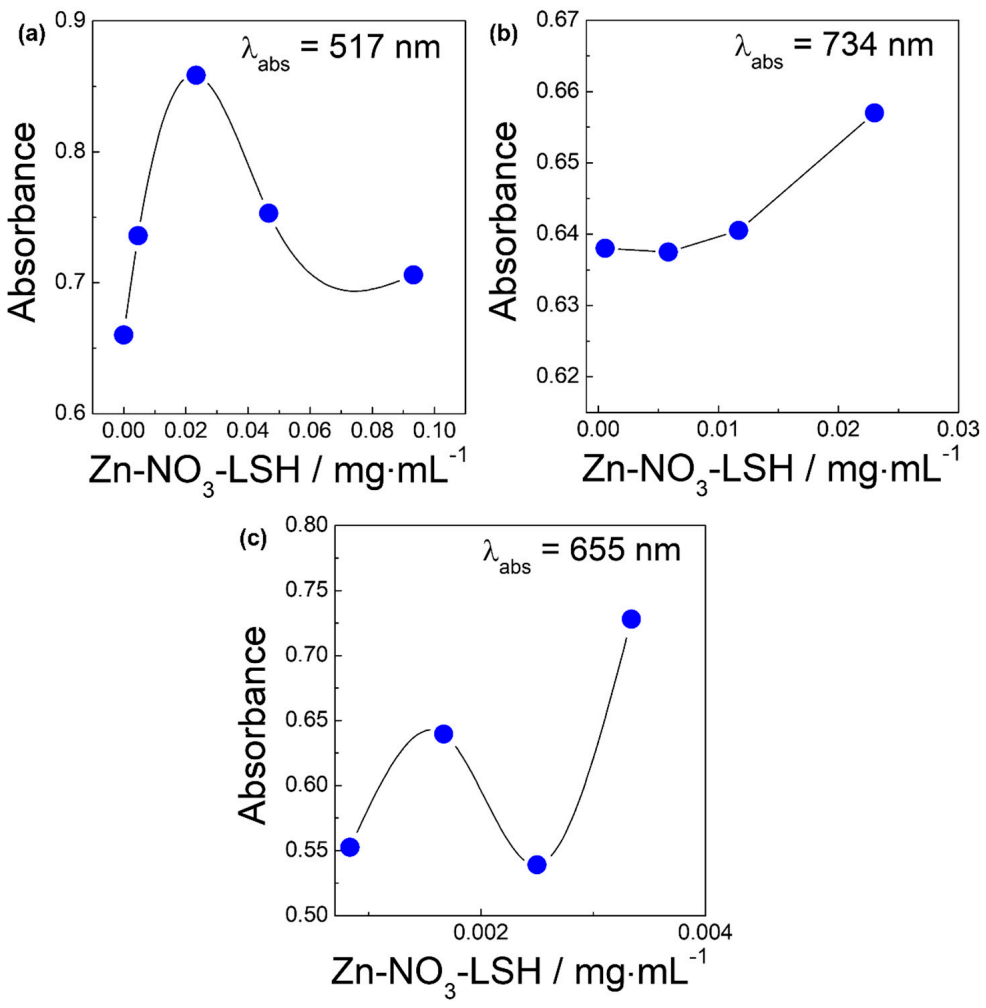

Figure A6. Average absorbance of (a) $\mathrm{DPPH}^{\bullet}$ and (b) $\mathrm{ABTS}^{\bullet+}$ reactive species as function of $\mathrm{Zn}-\mathrm{NO}_{3}-$ LSH concentration in the DPPH ${ }^{\bullet}$ and $\mathrm{ABTS}^{\bullet+}$ assay, respectively. Average absorbance of the (c) TMB chromophore in presence of $\mathrm{HOCl} / \mathrm{OCl}^{-}$species as function of host matrix concentration.

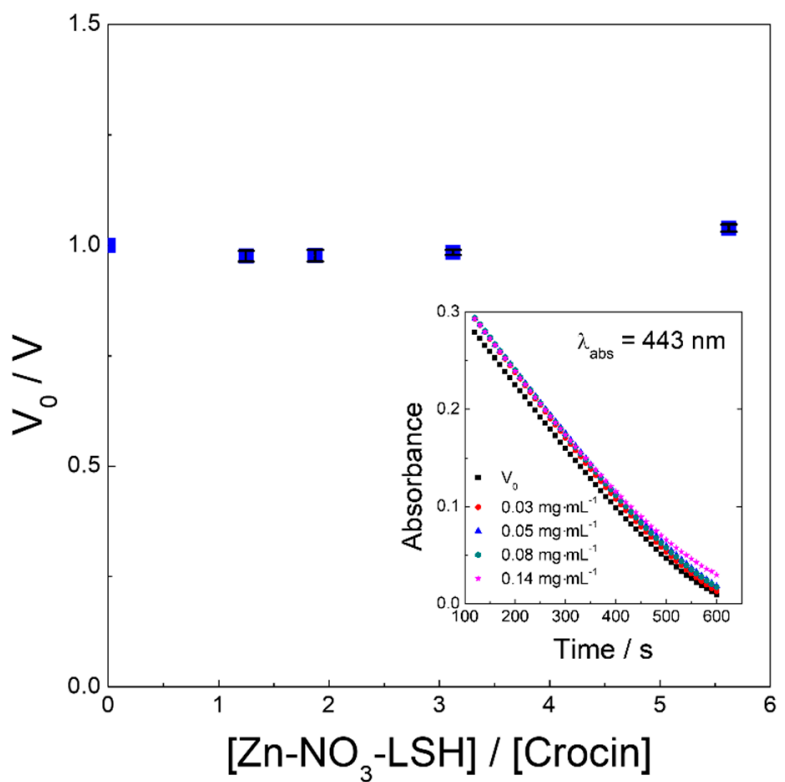

Figure A7. Representation between velocities and concentrations of the $\mathrm{Zn}-\mathrm{NO}_{3}-\mathrm{LSH}$ matrix in the crocin bleaching assay. $\mathrm{V}_{0}$, velocity in the absence of the host matrix; $\mathrm{V}$, velocity in the presence of the $\mathrm{Zn}-\mathrm{NO}_{3}$-LSH matrix. 

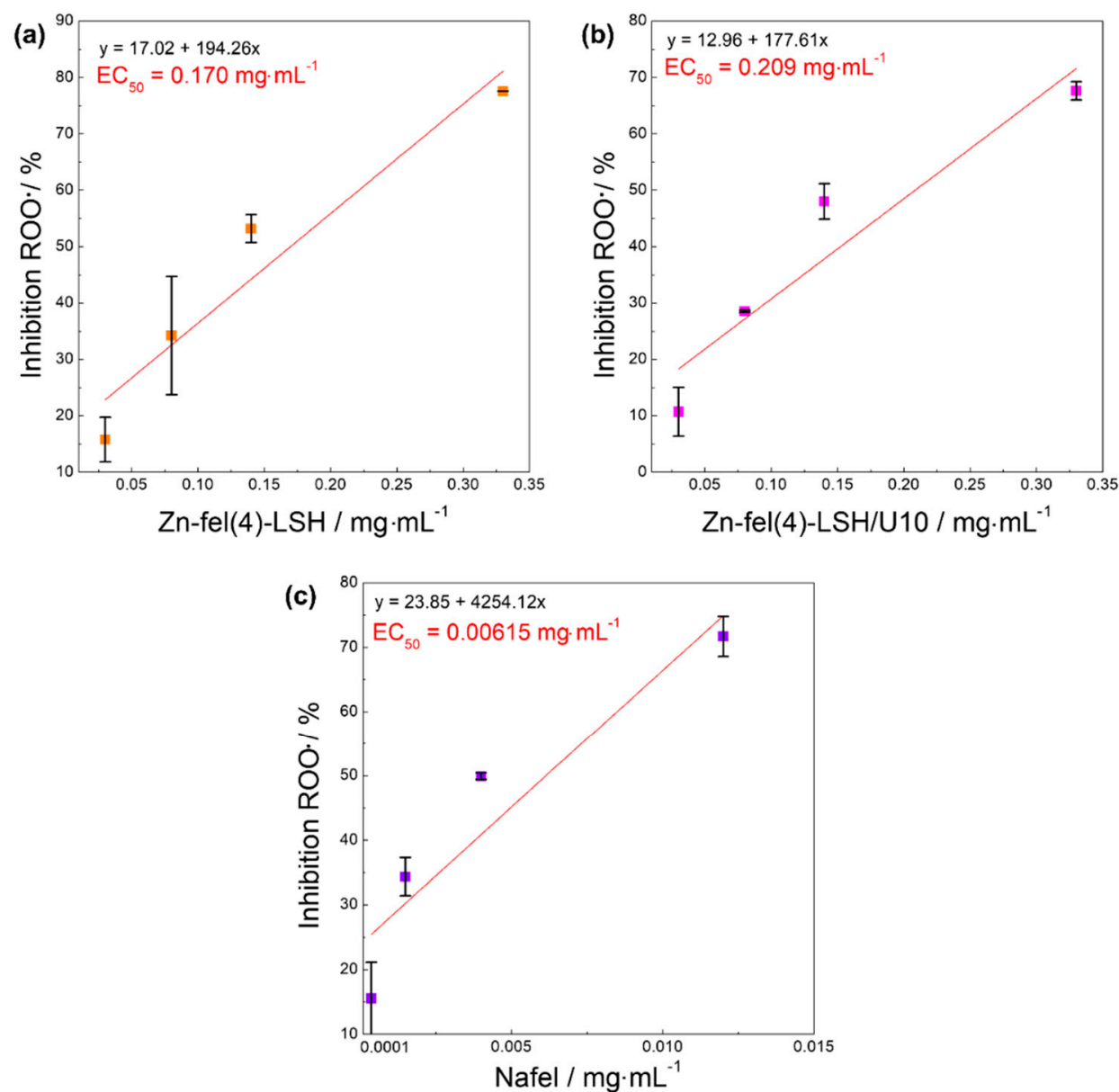

Figure A8. Inhibition (capture) of $\mathrm{ROO}^{\bullet}$ reactive species by (a) Zn-fel(4)-LSH, (b) Zn-fel(4)-LSH/U10 and (c) Nafel $\left(\mathrm{NaC}_{10} \mathrm{H}_{9} \mathrm{O}_{4}\right)$ samples.

\section{References}

1. Sarkar, S.; Gaddameedhi, S. Solar ultraviolet-induced DNA damage response: Melanocytes story in transformation to environmental melanomagenesis. Environ. Mol. Mutagen. 2020, 1-16. [CrossRef] [PubMed]

2. Powers, J.M.; Murphy, J.E.J. Sunlight radiation as a villain and hero: 60 years of illuminating research. Int. J. Radiat. Biol. 2019, 95, 1043-1049. [CrossRef] [PubMed]

3. Baker, L.A.; Marchetti, B.; Karsili, T.N.V.; Stavros, V.G.; Ashfold, M.N.R. Photoprotection: Extending lessons learned from studying natural sunscreens to the design of artificial sunscreen constituents. Chem. Soc. Rev. 2017, 46, 3770-3791. [CrossRef] [PubMed]

4. Sambandan, D.R.; Ratner, D. Sunscreens: An overview and update. J. Am. Acad. Dermatol. 2011, 64, 748-758. [CrossRef] [PubMed]

5. Kockler, J.; Oelgemöller, M.; Robertson, S.; Glass, B.D. Photostability of sunscreens. J. Photochem. Photobiol. C 2012, 13, 91-110. [CrossRef]

6. Huang, A.H.; Chien, A.L. Photoaging: A Review of Current Literature. Curr Derm Rep. 2020, 9, 22-29. [CrossRef]

7. Modenese, A.; Korpinen, L.; Gobba, F. Solar radiation exposure and outdoor work: An underestimated occupational risk. Int. J. Environ. Res. Public Health 2018, 15, 1-24. [CrossRef]

8. Hernández, J.M.G.; Escalante, A.; Vázquez, R.N.M.; Delgado, E.; González, F.J.; Toríz, G. Use of Agave tequilana-lignin and zinc oxide nanoparticles for skin photoprotection. J. Photochem. Photobiol. B 2016, 163, 156-161. [CrossRef]

9. Sukarno; Law, C.S.; Santos, A. Realisation and optical engineering of linear variable bandpass filters in nanoporous anodic alumina photonic crystals. Nanoscale 2017, 9, 7541-7550. [CrossRef]

10. Macleod, H.A. Thin-Films Optical Filters, 3rd ed.; Institute of Physics Publishing: Bristol, UK, 2001; pp. 1-641.

11. Saito, G.P.; Bizari, M.; Cebim, M.A.; Correa, M.A.; Jafelicci, M.; Davolos, M.R. Study of the colloidal stability and optical properties of sunscreen creams. Ecletica Quim J. 2019, 44, 26-36. [CrossRef]

12. Flor, J.; Davolos, M.R.; Correa, M.A. Sunscreens. Quim. Nova 2007, 30, 153-158. [CrossRef]

13. Saewan, N.; Jimtaisong, A. Natural products as photoprotection. J. Cosmet. Dermatol. 2015, 14, 47-63. [CrossRef]

14. Nunes, A.R.; Vieira, I.G.P.; Queiroz, D.B.; Leal, A.L.A.B.; Morais, S.M.; Muniz, D.F.; Calixto, J.T.; Coutinho, H.D.M. Use of flavonoids and cinnamates, the main photoprotectors with natural origin. Adv. Pharmacol. Sci. 2018, 2018, 1-9. [CrossRef] [PubMed] 
15. Kostyuk, V.; Potapovich, A.; Albuhaydar, A.R.; Mayer, W.; De Luca, C.; Korkina, L. Natural substances for prevention of skin photoaging: Screening systems in the development of sunscreen and rejuvenation cosmetics. Rejuvenation Res. 2018, $21,91-101$. [CrossRef] [PubMed]

16. Robbins, R.J. Phenolic acids in foods: An overview of analytical methodology. J. Agric. Food Chem. 2003, 51, 2866-2887. [CrossRef] [PubMed]

17. Dai, J.; Mumper, R.J. Plant phenolics: Extraction, analysis and their antioxidant and anticancer properties. Molecules 2010, 15, 7313-7352. [CrossRef] [PubMed]

18. Gunia-Krzyzak, A.; Sloczynska, K.; Popiol, J.; Koczurkiewicz, P.; Marona, H.; Pekala, E. Cinnamic acid derivatives in cosmetics: Current use and future prospects. Int. J. Cosmet. Sci. 2018, 40, 356-366. [CrossRef] [PubMed]

19. Hwang, S.H.; Han, Y.S.; Choy, J.H. Intercalation of functional organic molecules with pharmaceutical, cosmeceutical and nutraceutical functions into layered double hydroxides and zinc basic salts. Bull. Korean Chem. Soc. 2001, 22, 1019-1022.

20. Damiani, E.; Puglia, C. Nanocarriers and microcarriers for enhancing the UV protection of sunscreens: An overview. J. Pharm. Sci. 2019, 108, 3769-3780. [CrossRef]

21. Yin, H.; Tang, Z. Ultrathin two-dimensional layered metal hydroxides: An emerging platform for advanced catalysis, energy conversion and storage. Chem. Soc. Rev. 2016, 45, 4873-4891. [CrossRef]

22. Wypych, F.; Carbajal Arizaga, G.G. Intercalation and functionalization of brucite with carboxylic acids. Quim. Nova 2005, 28, 24-29. [CrossRef]

23. Carbajal Arizaga, G.G.; Satyanarayana, K.G.; Wypych, F. Layered hydroxide salts: Synthesis, properties and potential applications. Solid State Ionics 2007, 178, 1143-1162. [CrossRef]

24. Aisawa, S.; Ishida, E.; Takahashi, S.; Hirahara, H.; Narita, E. Synthesis and ultraviolet-ray-shielding property of organic UV-absorbent intercalated layered zinc hydroxide. Chem. Lett. 2005, 34, 630-631. [CrossRef]

25. Cursino, A.C.T.; Gardolinski, J.E.F.D.; Wypych, F. Intercalation of anionic organic ultraviolet ray absorbers into layered zinc hydroxide nitrate. J. Colloid Interface Sci. 2010, 347, 49-55. [CrossRef] [PubMed]

26. Cursino, A.C.T.; Mangrich, A.S.; Gardolinski, J.E.F.D.; Mattoso, N.; Wypych, F. Effect of confinement of anionic organic ultraviolet ray absorbers into two-dimensional zinc hydroxide nitrate galleries. J. Braz. Chem. Soc. 2011, 22, 1183-1191. [CrossRef]

27. Mohsin, S.M.N.; Hussein, M.Z.; Sarijo, S.H.; Fakurazi, S.; Arulselvan, P.; Hin, T.Y.Y. Synthesis of (cinnamate-zinc layered hydroxide) intercalation compound for sunscreen application. Chem. Cent. J. 2013, 7, 1-12. [CrossRef]

28. Cursino, A.C.T.; Rives, V.; Carlos, L.D.; Rocha, J.; Wypych, F. Layered Zinc Hydroxide Salts Intercalated with Anionic Surfactants and Adsolubilized with UV Absorbing Organic Molecules. J. Braz. Chem. Soc. 2015, 26, 1769-1780. [CrossRef]

29. Aziz, I.N.F.A.; Sarijo, S.H.; Rajidi, F.S.M.; Yahaya, R.; Musa, M. Synthesis and characterization of novel 4-aminobenzoate interleaved with zinc layered hydroxide for potential sunscreen application. J. Porous Mater. 2019, 26, 717-722. [CrossRef]

30. Ruiz, C.V.; Rodriguez-Castellon, E.; Giraldo, O. Structural Analysis and Conduction Mechanisms in Polycrystalline Zinc Hydroxide Nitrate. Inorg. Chem. 2018, 57, 9067-9078. [CrossRef]

31. Nogueira, T.; Wypych, F.; Mei, L.; Lona, L. Effect of layered hydroxide salts, produced by two different methods, on the mechanical and thermal properties of poly(methyl methacrylate). Polym. Eng. Sci. 2019, 59, 1065-1074. [CrossRef]

32. Stählin, W.; Oswald, H.R. The crystal structure of zinc hydroxide nitrate, $\mathrm{Zn}_{5}(\mathrm{OH})_{8}\left(\mathrm{NO}_{3}\right)_{2} \cdot 2 \mathrm{H}_{2} \mathrm{O}$. Acta Cryst. 1970, $26,860-863$. [CrossRef]

33. Marangoni, R.; Ramos, L.P.; Wypych, F. New multifunctional materials obtained by the intercalation of anionic dyes into layered zinc hydroxide nitrate followed by dispersion into poly(vinyl alcohol) (PVA). J. Colloid Interface Sci. 2009, 330, 303-309. [CrossRef] [PubMed]

34. Roth, W.J.; Gil, B.; Makowski, W.; Marszalek, B.; Eliasova, P. Layer like porous materials with hierarchical structure. Chem. Soc. Rev. 2016, 45, 3400-3438. [CrossRef] [PubMed]

35. Shchukin, D.G.; Skorb, E.; Belova, V.; Mohwald, H. Ultrasonic Cavitation at Solid Surfaces. Adv. Mater. 2011, $23,1922-1934$. [CrossRef] [PubMed]

36. Rojas, R.; Giacomelli, C.E. Effect of structure and bonding on the interfacial properties and the reactivity of layered double hydroxides and Zn hydroxide salts. Colloids Surf. A 2013, 419, 166-173. [CrossRef]

37. Ruiz, C.V.; Becerra, M.E.; Giraldo, O. Structural, thermal, and release properties of hybrid materials based on layered zinc hydroxide and caffeic acid. Nanomaterials 2020, 10, 163. [CrossRef] [PubMed]

38. Cano-Sarmiento, C.; Tellez-Medina, D.I.; Viveros-Contreras, R.; Cornejo-Mazon, M.; Figueroa-Hernandez, C.Y.; Garcia- Armenta, E.; Alamilla-Beltran, L.; Garcia, H.S.; Gutierrez-Lopez, G.F. Zeta Potential of Food Matrices. Food Eng. Rev. 2018, 10, 113-138. [CrossRef]

39. Bhattacharjee, S. DLS and zeta potential—What they are and what they are not? J. Control. Release 2016, 235, 337-351. [CrossRef]

40. Xu, Z.P.; Jin, Y.G.; Liu, S.M.; Hao, Z.P.; Lu, G.Q. Surface charging of layered double hydroxides during dynamic interactions of anions at the interfaces. J. Colloid Interface Sci. 2008, 326, 522-529. [CrossRef]

41. Machado, G.S.; Arizaga, G.G.C.; Wypych, F.; Nakagaki, S. Immobilization of anionic metalloporphyrins on zinc hydroxide nitrate and study of an unusual catalytic activity. J. Catal. 2010, 274, 130-141. [CrossRef]

42. Nakamoto, K. Infrared and Raman Spectra of Inorganic and Coordination Compounds, 5th ed.; John Wiley \& Sons: New York, NY, USA, 1997; pp. 1-484. 
43. Kang, H.; Kim, H.J.; Yang, J.H.; Kim, T.H.; Choi, G.; Paek, S.M.; Choi, A.J.; Choy, J.H.; Oh, J.M. Intracrystalline structure and release pattern of ferulic acid intercalated into layered double hydroxide through various synthesis routes. Appl. Clay Sci. 2015, 112, 32-39. [CrossRef]

44. Olga, G.; Styliani, C.; Ioannis, R.G. Coencapsulation of Ferulic and Gallic acid in hp-b-cyclodextrin. Food Chem. 2015, 185, 33-40. [CrossRef] [PubMed]

45. Pavia, D.L.; Lampman, G.M.; Kriz, G.S.; Vyvyan, J.R. Infrared Spectroscopy. In Introduction to Spectroscopy, 5th ed.; Cengage Learning: Stamford, CT, USA, 2013; pp. 14-106.

46. Deacon, G.B.; Phillips, R.J. Relationships between the carbon-oxygen stretching frequencies of carboxilato complexes and the type of carboxylate coordination. Coord. Chem. Rev. 1980, 33, 227-250. [CrossRef]

47. Ahmed, A.A.A.; Talib, Z.A.; bin Hussein, M.Z.; Zakaria, A. Zn-Al layered double hydroxide prepared at different molar ratios: Preparation, characterization, optical and dielectric properties. J. Solid State Chem. 2012, 191, 271-278. [CrossRef]

48. Junior Quites, F.; Germino, J.C.; Atvars, T.D.Z. Improvement in the emission properties of a luminescent anionic dye intercalated between the lamellae of zinc hydroxide-layered. Colloids Surf. A 2014, 459, 194-201. [CrossRef]

49. Wang, J.; Cao, Y.; Sun, B.; Wang, C. Characterisation of inclusion complex of trans-ferulic acid and hydroxypropyl- $\beta$-cyclodextrin. Food Chem. 2011, 124, 1069-1075. [CrossRef]

50. Pavia, D.L.; Lampman, G.M.; Kriz, G.S.; Vyvyan, J.R. Ultraviolet Spectroscopy. In Introduction to Spectroscopy, 5th ed.; Cengage Learning: Stamford, CT, USA, 2013; pp. 577-613.

51. Stanfield, J.; Osterwalder, U.; Herzog, B. In vitro measurements of sunscreen protection. Photochem. Photobiol. Sci. 2010, 9, 489-494. [CrossRef]

52. Binks, B.P.; Fletcher, P.D.I.; Johnson, A.J.; Marinopoulos, I.; Crowther, J.; Thompson, M.A. How the sun protection factor (SPF) of sunscreen films change during solar irradiation. J. Photochem. Photobiol. A 2017, 333, 186-199. [CrossRef]

53. Wang, S.Q.; Lim, H.W. Current status of the sunscreen regulation in the United States: 2011 Food and Drug Administration's final rule on labeling and effectiveness testing. J. Am. Acad. Dermatol. 2011, 65, 863-869. [CrossRef]

54. Passeron, T.; Bouillon, R.; Callender, V.; Cestari, T.; Diepgen, T.L.; Green, A.C.; van der Pols, J.C.; Bernard, B.A.; Ly, F.; Bernerd, F.; et al. Sunscreen photoprotection and vitamin D status. Br. J. Dermatol. 2019, 181, 916-931. [CrossRef]

55. Chan, T.C.W.; Berka, J.L.W.; Deliyanti, D.; Hunter, D.; Fung, A.; Liew, G.; White, A. The role of reactive oxygen species in the pathogenesis and treatment of retinal diseases. Exp. Eye Res. 2020, 201, 108255. [CrossRef]

56. Lúcio, M.; Nunes, C.; Gaspar, D.; Ferreira, H.; Lima, J.L.F.C.; Reis, S. Antioxidant activity of vitamin E and trolox: Understanding of the factors that govern lipid peroxidation studies in vitro. Food Biophys. 2009, 4, 312-320. [CrossRef]

57. Spagnol, C.M.; Assis, R.P.; Brunetti, I.L.; Isaac, V.L.B.; Salgado, H.R.N.; Corrêa, M.A. In vitro methods to determine the antioxidant activity of caffeic acid. Spectrochim. Acta Part A 2019, 219, 358-366. [CrossRef] [PubMed]

58. Saito, G.P.; Romero, J.H.S.; Cebim, M.A.; Davolos, M.R. Eu(III) doped LDH intercalated with cinnamate anion as multifunctional sunscreens. J. Lumin. 2018, 203, 160-164. [CrossRef]

59. Franco, J.G.; Ataide, J.A.; Ferreira, A.H.P.; Mazolla, P.G. Lamellar compounds intercalated with anions with solar protection function: A review. J. Drug. Deliv. Sci. Technol. 2020, 59, 1-5. [CrossRef]

60. Prior, R.L.; Wu, X.; Schaich, K. Standardized methods for the determination of antioxidant capacity and phenolics in foods and dietary supplements. J. Agric. Food Chem. 2005, 53, 4290-4302. [CrossRef] [PubMed]

61. Almeida, M.G.J.; Chiari, B.G.; Corrêa, M.A.; Chung, M.C.; Isaac, V.L.B. Validation of an alternative analytical method for the quantification of antioxidant activity in plant extracts. Lat. Am. J. Pharm. 2013, 32, 90-95.

62. Lapenna, D.; Cuccurullo, F. Hypochlorous acid and its pharmacological antagonism: An update picture. Gen. Pharmacol. 1996, 27, 1145-1147. [CrossRef]

63. Assis, R.P.; Castro, J.F.A.; Gutierres, V.O.; Arcaro, C.A.; Brotto, R.S.; Olga Oliveira, M.M.F.; Baviera, A.M.; Brunetti, I.L. Effects of uremic solutes on reactive oxygen species in vitro model systems as a possibility of support the renal function management. BMC Nephrol. 2015, 16, 1-13. [CrossRef]

64. Gers-Barlag, H.; Klette, E.; Bimczok, R.; Springob, C.; Finkel, P.; Rudolph, T.; Gonzenbach, H.U.; Schneider, P.H.; Kockott, D.; Heinrich, U.; et al. In vitro testing to assess the UVA protection performance of sun care products. Int. J. Cosmet. Sci. 2001, 23, 3-14.

65. ISO 24443:2012. Determination of Sunscreen UVA Photoprotection In Vitro, International Organization for Standardization; ISO: Geneva, Switzerland, 2012.

66. Berni, A.; Mennig, M.; Schmidt, H. Doctor Blade. In Sol-Gel Technologies for Glass Producers and Users; Aegerter, M.A., Mennig, M., Eds.; Springer: Boston, MA, USA, 2004; pp. 89-92.

67. Soares, J.R.; Dinis, T.C.P.; Cunha, A.P.; Almeida, L.M. Antioxidant Activities of Some Extracts of Thymus zygis. Free Rad. Res. 1997, 26, 469-478. [CrossRef]

68. Re, R.; Pellegrini, N.; Proteggente, A.; Pannala, A.; Yang, M.; Rice-Evans, C. Antioxidant activity applying improved ABTS radical cation decolorization assay. Free Radic. Biol. Med. 1999, 26, 1231-1237. [CrossRef]

69. Zgliczynski, J.M.; Stelmaszynska, T.; Domanska, J.; Ostrowski, W. Chloramines as intermediates of oxidation reaction of amino acids by myeloperoxidase. Biochem. Biophys. Acta. 1971, 235, 419-424. [CrossRef] 
70. Dypbukt, J.M.; Bishop, C.; Brooks, W.M.; Thong, B.; Eriksson, H.; Kettle, A.J. A sensitive and selective assay for chloramine production by myeloperoxidase. Free Radic. Biol. Med. 2005, 39, 1468-1477. [CrossRef] [PubMed]

71. Tubaro, F.; Ghiselli, A.; Rapuzzi, P.; Maiorino, M.; Ursini, F. Analysis of plasma antioxidant capacity by competition kinetics. Free Radic. Biol. Med. 1998, 24, 1228-1234. [CrossRef] 